\section{OPEN ACCESS}

Edited by:

Lin-Hua Jiang

University of Leeds, United Kingdom

Reviewed by:

Yasuo Mori

Kyoto University, Japan

Rodrigo Franco,

University of Nebraska-Lincoln,

United States

*Correspondence:

Michael X. Zhu

Michael.X.Zhu@uth.tmc.edu

Specialty section: This article was submitted to

Signaling,

a section of the journal Frontiers in Cell and Developmental

Biology

Received: 17 October 2020

Accepted: 11 December 2020

Published: 08 January 2021

Citation:

Jeon J, Bu F, Sun G, Tian J-B,

Ting S-M, Li J, Aronowski J, Birnbaumer L, Freichel $M$ and Zhu MX

(2021) Contribution of TRPC

Channels in Neuronal Excitotoxicity Associated With Neurodegenerative

Disease and Ischemic Stroke.

Front. Cell Dev. Biol. 8:618663. doi: 10.3389/fcell.2020.618663

\title{
Contribution of TRPC Channels in Neuronal Excitotoxicity Associated With Neurodegenerative Disease and Ischemic Stroke
}

\begin{abstract}
Jaepyo Jeon', Fan Bu², Guanghua Sun', Jin-Bin Tian', Shun-Ming Ting' ${ }^{2}$ Jun $L i^{2}$, Jaroslaw Aronowski ${ }^{2}$, Lutz Birnbaumer ${ }^{3,4,5}$, Marc Freichel ${ }^{6,7}$ and Michael X. Zhu ${ }^{1 *}$
\end{abstract}

\begin{abstract}
'Department of Integrative Biology and Pharmacology, McGovern Medical School, The University of Texas Health Science Center at Houston, Houston, TX. United States, ${ }^{2}$ Department of Neurology, McGovern Medical School, The University of Texas Health Science Center at Houston, Houston, TX, United States, ${ }^{3}$ Institute for Biomedical Research (BIOMED UCA-CONICET), Buenos Aires, Argentina, ${ }^{4}$ School of Medical Sciences, Catholic University of Argentina (UCA), Buenos Aires, Argentina, ${ }^{5}$ Neurobiology Laboratory, National Institute of Environmental Health Sciences, Durham, NC, United States, ${ }^{6}$ Department of Pharmacology, Heidelberg University, Heidelberg, Germany, ${ }^{7}$ DZHK (German Centre for Cardiovascular Research), partner site Heidelberg/Mannheim, Heidelberg, Germany
\end{abstract}

The seven canonical members of transient receptor potential (TRPC) proteins form cation channels that evoke membrane depolarization and intracellular calcium concentration $\left(\left[\mathrm{Ca}^{2+}\right]_{i}\right)$ rise, which are not only important for regulating cell function but their deregulation can also lead to cell damage. Recent studies have implicated complex roles of TRPC channels in neurodegenerative diseases including ischemic stroke. Brain ischemia reduces oxygen and glucose supply to neurons, i.e., Oxygen and Glucose Deprivation (OGD), resulting in $\left[\mathrm{Ca}^{2+}\right]_{i}$ elevation, ion dyshomeostasis, and excitotoxicity, which are also common in many forms of neurodegenerative diseases. Although ionotropic glutamate receptors, e.g., $N$-methyl-D-aspartate receptors, are well established to play roles in excitotoxicity, the contribution of metabotropic glutamate receptors and their downstream effectors, i.e., TRPC channels, should not be neglected. Here, we summarize the current findings about contributions of TRPC channels in neurodegenerative diseases, with a focus on OGD-induced neuronal death and rodent models of cerebral ischemia/reperfusion. TRPC channels play both detrimental and protective roles to neurodegeneration depending on the TRPC subtype and specific pathological conditions involved. When illustrated the mechanisms by which TRPC channels are involved in neuronal survival or death seem differ greatly, implicating diverse and complex regulation. We provide our own data showing that TRPC1/C4/C5, especially TRPC4, may be generally detrimental in OGD and cerebral ischemia/reperfusion. We propose that although TRPC channels significantly contribute to ischemic neuronal death, detailed mechanisms and specific roles of TRPC subtypes in brain injury at different stages of ischemia/reperfusion and in different brain regions need to be carefully and systematically investigated.

Keywords: neurological disease, TRPC4 knockout, calcium, neuroprotection, neurodegeneration, neuronal death 


\section{INTRODUCTION}

Stroke occurs when a part of the brain is deprived of oxygen and glucose. Each year, about 795,000 Americans suffer a new or recurrent stroke, making it the No. 5 cause of death and a leading cause of disability in the United States (Virani et al., 2020). In $70-80 \%$ of the cases, the precipitating cause of stroke is a blood clot that blocks the supply of oxygenated blood to a region of the brain, a situation termed ischemic stroke (Woodruff et al., 2011). The damage to neurons during ischemia is caused by a reduction of oxygen and glucose supply, i.e., oxygen and glucose deprivation (OGD) (Ying et al., 1997; Lipton, 1999).

Cell death after cerebral ischemia may result from a number of events, including acidosis, inflammation, generation of arachidonic acid, elevation in intracellular calcium concentrations $\left(\left[\mathrm{Ca}^{2+}\right]_{i}\right)$, loss of cellular ion homeostasis, free radical-mediated toxicity, energy failure, infiltration of leukocytes, cytokine-mediated cytotoxicity and glutamateinduced excitotoxicity (Woodruff et al., 2011). Particularly, excessive extracellular glutamate can elicit multiple neurotoxic effects. Initially, energy depletion-induced depolarization of the neuronal membrane leads to the influx of $\mathrm{Ca}^{2+}$ through voltage-gated $\mathrm{Ca}^{2+}$ channels (VGCCs), which triggers $\mathrm{Ca}^{2+}$-dependent glutamate release from axonal terminals of excitatory neurons (Bonde et al., 2005). In the past, much of the focus on glutamate-induced excitotoxicity had been on ionotropic glutamate receptors (iGluRs), mainly NMDA (N-methyl-D-aspartate) receptors and AMPA (a-amino-3hydroxy-5-methyl-4-isoxazolepropionic acid) receptors, but more recently, metabotropic glutamate receptors (mGluRs) have also been recognized to play a crucial role in excitotoxicity (Hilton et al., 2006).

The mGluR family consists of three groups, group I-III, and 8 subtypes, mGluR1-8, of which the group I mGluRs, i.e., mGluR1 and mGluR5, are coupled to $G_{q / 11}$-phospholipase C (PLC) pathway and the rest are all linked to $\mathrm{G}_{i / o}$ proteins (Swanson et al., 2005). On one hand, the activation of $\mathrm{G}_{q / 11^{-}}$ PLC pathway by glutamate through stimulation of mGluR1/5 is to enhance neuronal excitability via a number of mechanisms, such as the suppression of $\mathrm{K}^{+}$channels caused by the breakdown of phosphatidylinositol 4,5-bisphosphate $\left(\mathrm{PIP}_{2}\right)$, a phospholipid that supports the activity of many $\mathrm{K}^{+}$channels (Hille et al., $2015)$, and the production of inositol 1,4,5-trisphosphate $\left(\mathrm{IP}_{3}\right)$, a second messenger that acts at the $\mathrm{IP}_{3}$ receptors to mobilize $\mathrm{Ca}^{2+}$ from the endoplasmic reticulum (ER) $\mathrm{Ca}^{2+}$ stores (Berridge, 2009). On the other hand, the activation of $\mathrm{G}_{i / o}$-coupled group II and group III mGluRs are generally thought to inhibit neuronal excitation through, among others, activation of $G$ proteingated inwardly rectifying $\mathrm{K}^{+}$(GIRK) channels and inhibition of VGCCs (Logothetis et al., 2015). Therefore, the excessive extracellular glutamate associated with OGD may lead to both excitatory and inhibitory effects through mGluRs depending on the abundance and types of the mGluRs and downstream signaling pathways involved.

A major class of $\mathrm{Ca}^{2+}$-permeable non-selective cation channels activated downstream from mGluRs is the Transient Receptor Potential Canonical (TRPC) channels. The TRPC channel family consists of 7 members, TRPC1-7, in which TRPC2 is a pseudogene in humans (Montell et al., 2002). These channels are typically activated downstream from receptors linked to PLC signaling, with $G_{q / 11}$-PLC $\beta$ pathway being the most common. Thus, glutamate activation of $\mathrm{G}_{q / 11}$-coupled mGluR1/5 is likely linked to TRPC channel activation, leading to consequent membrane depolarization and $\left[\mathrm{Ca}^{2+}\right]_{i}$ elevation. Ironically, despite the widespread expression of TRPCs in brain neurons (Riccio et al., 2002) and their much-longer lasting activities in response to $\mathrm{G}_{q / 11}$-PLC $\beta$ signaling than iGluRs (Hartmann et al., 2008; Riccio et al., 2009), not much is known about the contributions of TRPC channels in excitotoxicity to neurons except for a few examples. It was shown that in the pilocarpine-induced epilepsy model, the epileptiform burst firing in lateral septal and hippocampal neurons involves the activation of TRPC channels downstream from mGluRs, which is critical for the glutamate excitotoxicity (Phelan et al., 2012, 2013; Zheng and Phelan, 2014). In brain injury induced by focal cerebral ischemia, the roles of TRPC channels can be rather complex. For instance, while TRPC1 and TRPC4 mediate glutamate-induced neuronal death, TRPC6 may exert a protective role against ischemic neuronal death (Du et al., 2010).

Here, we explore the current evidence on contributions of TRPC channels in ischemic neuronal death, taking into account that these channels are activated downstream from mGluRs and likely work in concert with VGCCs and iGluRs to induce neuronal excitation and produce $\left[\mathrm{Ca}^{2+}\right]_{i}$ signals, and such activities can have a pivotal impact on glutamate excitotoxicity. Because excitotoxicity occurs commonly in many types of neurodegenerative diseases, including Alzheimer's disease, epilepsy, Huntington's disease, and Parkinson's disease, we also discuss the involvement of TRPC channels in these diseases in attempt to shed some lights on the mechanistic insights of TRPC regulation of excitotoxicity. Finally, we present some of our own data demonstrating the specific role of TRPC4/C5 channels in ischemic cell death and neuroprotective potential of targeting these channels using small molecular probes.

\section{THE BASIS OF EXCITOTOXIC NEURONAL DEATH IN ISCHEMIC STROKE}

Cerebral ischemic stroke is caused by interruption of blood supply through the middle cerebral artery (MCA). The MCA has large surface branches to supply blood into its territory that encompasses almost the entire boundary of the cortex and white matter of the hemisphere, including the major lobes (frontal, parietal, temporal, and occipital) and insula cortex (Brust, 2013). Occlusion of the MCA (MCAO) is the most frequently encountered stroke signs and symptoms, which may produce paralysis on the left or right side of the body, vision loss, and speech impairment (Rathore et al., 2002). The neurological deficits in ischemic stroke resulted from the deprivation of glucose and oxygen supply, or OGD, which leads to brain tissue damages. When the MCAO is prolonged, neurons lose glucosedependent ATP generation, which in turn disrupts electrogenic 
pumps, e.g., plasma membrane $\mathrm{Ca}^{2+}$ ATPase (PMCA) and $\mathrm{Na}^{+} / \mathrm{K}^{+}$ATPase.

The failure of the ATPases subsequently results in $\left[\mathrm{Ca}^{2+}\right]_{i}$ increase and membrane depolarization, which causes glutamate release, as well as an elevation of extracellular $\mathrm{K}^{+}$concentration. These also alter the ionic composition of the cytoplasm, with increases in $\mathrm{Na}^{+}, \mathrm{Ca}^{2+}$, and $\mathrm{Cl}^{-}$and a decrease in $\mathrm{K}^{+}$ levels, leading to an osmolarity change and more commonly hyperosmolarity (Tanaka et al., 1997; Tanaka et al., 1999; Brisson and Andrew, 2012). Consequently, the inflow of water into the neuron in response to the osmolality change causes cell swelling and disruption of the membrane structure, which constitutes one of the multiple causes of neuronal death (Toyoda et al., 2020).

In addition to ionic imbalance caused by the failure of ATPases, excessive extracellular accumulation of glutamate also leads to toxic increases in $\left[\mathrm{Ca}^{2+}\right]_{i}$, which activate multiple signaling pathways and ultimately lead to cell death (Durukan and Tatlisumak, 2007; Doyle et al., 2008). For many years, NMDA and AMPA receptors have been considered the pivotal targets of excitotoxicity associated with ischemic stroke. The activation of postsynaptic NMDA and AMPA receptors by synaptic glutamate causes membrane depolarization and $\mathrm{Ca}^{2+}$ influx, which definitely accounts for excitotoxicity. However, this is not the only way by which glutamate can elicit excitotoxicity. The abundant presence of mGluRs in both pre- and postsynaptic membranes, as well as extrasynaptic membranes, suggests that these metabotropic receptors are also activated under conditions of excessive glutamate release and accumulation both inside and outside the synapse. At least for mGluR1 and mGluR5, the activation will increase excitability through $\left[\mathrm{Ca}^{2+}\right]_{i}$ elevation first by causing $\mathrm{ER} \mathrm{Ca}^{2+}$ release. This will be followed by store- and/or receptor-operated $\mathrm{Ca}^{2+}$ entry, and in the case of coupling to TRPC channels, the activation of these mGluRs will also lead to membrane depolarization, given the nonselective nature of these channels, and the subsequent $\mathrm{Ca}^{2+}$ influx through both TRPC channels and VGCCs. Although permeable to both $\mathrm{Na}^{+}$and $\mathrm{Ca}^{2+}$ as the NMDA and AMPA receptors, the conductance and activation kinetics of TRPC channels are vastly different from that of the iGluRs, typically being slower and longer lasting than the iGluRs as has been demonstrated during synaptic transmission (Hartmann et al., 2008; Riccio et al., 2009; Pressler and Regehr, 2013; Reiner and Levitz, 2018). Thus, in addition to iGluRs, the mGluRTRPC coupling represents another main mechanism by which glutamate can induce excitotoxicity through $\left[\mathrm{Ca}^{2+}\right]_{i}$ elevation and membrane depolarization, along with the consequent ionic imbalance, osmolarity changes and $\mathrm{Ca}^{2+}$ signaling (Toyoda et al., 2020), resulting in spatiotemporally distinct signaling effects that work in concert with those generated by iGluRs to induce cell demise.

Importantly, in spite of the promising results in reducing ischemic damage of brain tissues in animal models and the tremendous efforts made, antagonists of NMDA and AMPA receptors have not been effective in terms of neuroprotection against brain injury associated with ischemic stroke in clinical trials. Therefore, it would be beneficial to gain a better understanding of ischemic stroke pathology of the brain by exploring additional pathways, which will help identify new therapeutic candidates and approaches. Based on the current literature and our own experimental findings, we propose that TRPC channels play a critical part in neurological damage associated with ischemic stroke and should be evaluated as viable therapeutic targets for neuroprotection (Figure 1).

\section{THE ROLES OF TRPC CHANNELS IN CELL DEATH}

The seven mammalian TRPC members are divided into 4 subgroups (TRPC1, TRPC2, TRPC3/6/7, and TRPC4/5). Among them, TRPC1, C3, C4, C5, and C6 are highly expressed in neurons at various brain regions, with distinct distributions and functions; for example, TRPC3 is highly expressed in cerebellar Purkinje neurons and involved in motor coordination, TRPC4 and TRPC5 are highly expressed in cerebral cortex, hippocampus and amygdala and functionally implicated in anxiety and fear learning (Clapham, 2003; Venkatachalam and Montell, 2007; Hartmann et al., 2008; Riccio et al., 2009; Riccio et al., 2014). In general, the TRPC channels in neurons are activated downstream from stimulation of $\mathrm{G}_{q / 11}$-coupled receptors, including mGluR1/5 (Kim et al., 2003; El-Hassar et al., 2011; Phelan et al., 2012), M1 muscarinic receptors (Yan et al., 2009; Tai et al., 2011), 5-HT2 serotonin receptor (Munsch et al., 2003; Sohn et al., 2011; Gao et al., 2017), H1 histamine receptor (Tabarean, 2012), kisspeptin receptor (Zhang et al., 2008), cholecystokinin (CCK) type 1 and type 2 receptors (Riccio et al., 2009; Wang et al., 2011), and thyrotropin-releasing hormone (TRH) receptors (Zhang et al., 2015). In addition, receptor tyrosine kinases, such as TrkB receptor through stimulation by brain-derived neurotrophic factor (BDNF) (Amaral and Pozzo-Miller, 2007; Li et al., 2010) and leptin receptor by leptin (Qiu et al., 2010), are also linked to TRPC channel activation in neurons through activation of PLC $\gamma$ 's. However, there are some exceptions. For instance, in olfactory bulb granule cells, the TRPC1/C4 heteromeric channels are dependent on NMDA receptors, instead of mGluRs, for activation that causes long lasting depolarization and sustained $\mathrm{Ca}^{2+}$ influx (Storch et al., 2012); the activation of TRPC-like channels in thalamic paraventricular nucleus neurons requires not only the $G_{q / 11}$-coupled thyrotropin-releasing hormone

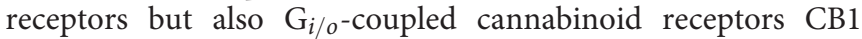
and CB2 (Zhang et al., 2015). This latter observation is very interesting in light of the recent findings that receptor-operated activation of TRPC4-containing channels requires coincident stimulation of $\mathrm{G}_{i / o}$ protein signaling and PLC activities (Thakur et al., 2016, 2020; Jeon et al., 2020). In addition, some TRPC channels are also reported to be activated by nitric oxide, reactive oxygen species (ROS), thioredoxin, and $\mathrm{Ca}^{2+}$ store depletion (Yoshida et al., 2006; Xu et al., 2008; Ogawa et al., 2016). For more comprehensive discussions on activation mechanisms of TRPC channels, readers are referred to our recent review article (Wang et al., 2020).

All TRPC proteins form $\mathrm{Ca}^{2+}$-permeable non-selective cation channels, which are tetramers composed of either identical (homotetramers) or different (heterotetramers) TRPC subunits. 


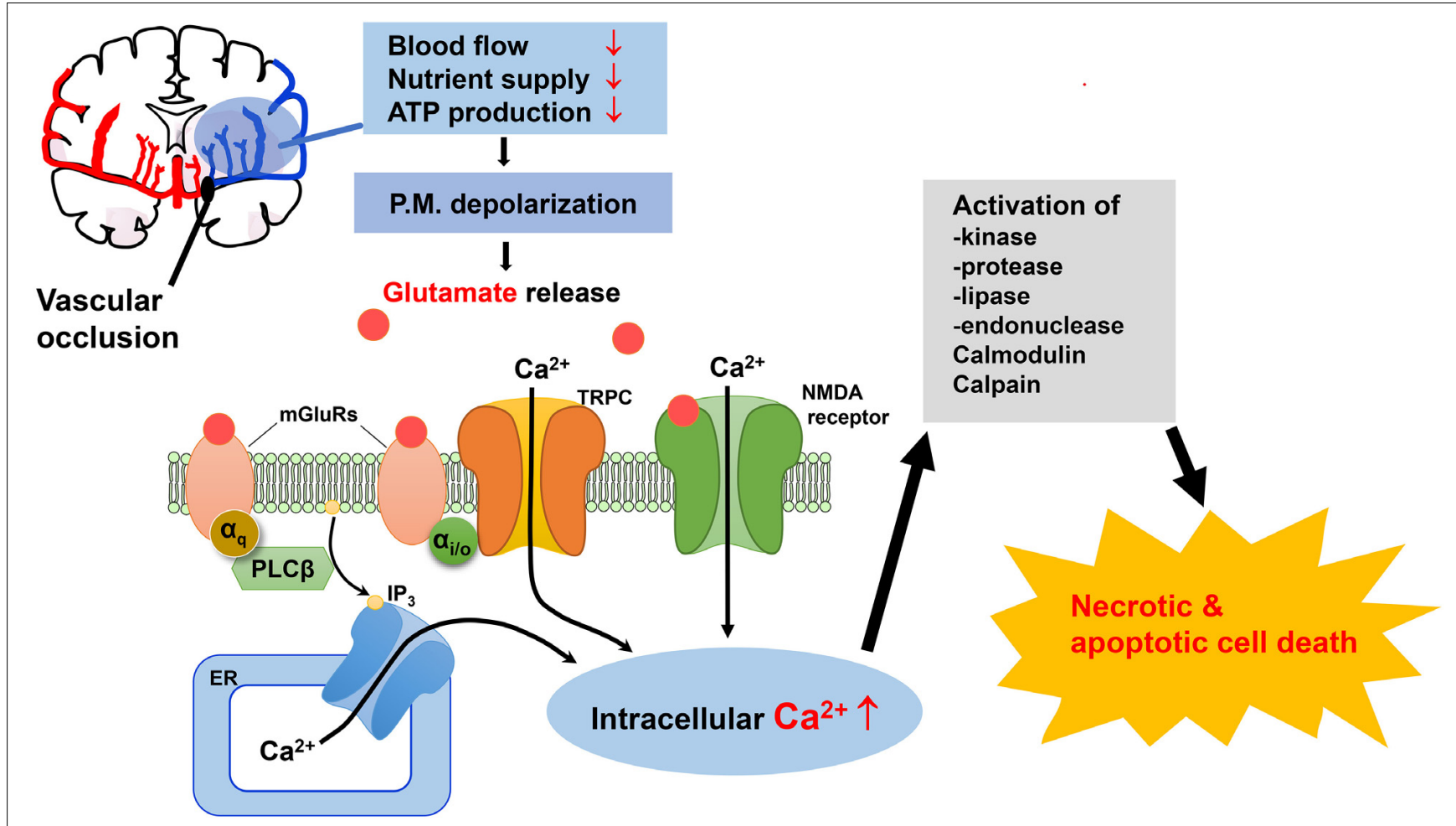

FIGURE 1 | Possible mechanisms for the involvement of TRPC channels in excitotoxic neuronal death in ischemic stroke. Oxygen and glucose deprivation due to the blockade of blood flow to brain areas in ischemic stroke causes excess accumulation of extracellular glutamate. The subsequent activation of NMDA receptors and mGluRs causes elevation of intracellular $\mathrm{Ca}^{2+}$ levels through $\mathrm{Ca}^{2+}$ influx from extracellular space and $\mathrm{Ca}^{2+}$ release from the ER, respectively. TRPC channels are activated downstream from mGluRs, causing more sustained $\mathrm{Ca}^{2+}$ elevation by mediating additional $\mathrm{Ca}^{2+}$ influx. TRPC4 and TRPC 5 channels are also activated downstream from mGluR subtypes that couple to PTX-sensitive $G_{i / o}$ proteins, further expanding the repertoire of receptors that convey glutamate stimulation to $\mathrm{Ca}^{2+}$ signaling. Moreover, membrane depolarization resulting from activation of NMDA receptors and TRPC channels leads to excitation which also triggers additional $\mathrm{Ca}^{2+}$ influx through voltage-gated $\mathrm{Ca}^{2+}$ channels. The rise in intracellular $\mathrm{Ca}^{2+}$ due to these mechanisms causes activity changes of a plethora of enzymes, ion channels and transcription factors, as well as mitochondria, which when dysregulated induce cell death via either necrosis or apoptosis. ER, endoplasmic reticulum; $\mathrm{IP}_{3}$, inositol 1,4,5-trisphosphate; mGluRs, metabotropic glutamate receptors; NMDA, N-methyl-D-aspartate; P.M., plasma membrane; PTX, pertussis toxin.

Among the seven TRPC isoforms, TRPC1 has been the most frequently studied in the context of heteromeric channels (Storch et al., 2012), especially in the forms of TRPC1/C4 and TRPC1/C4/C5 heteromers (Phelan et al., 2012; Storch et al., 2012; Broker-Lai et al., 2017). However, TRPC1/C3 heteromers also form, at least in cortical astrocytes where they regulate astrogliosis in response to traumatic brain injury (Belkacemi et al., 2017). As is the case of TRPC1/C4 and TRPC1/C5 channels where TRPC1 reduced the channel conductance (Strubing et al., 2001), TRPC1 also serves to dampen the $\mathrm{Ca}^{2+}$ signal and the astrogliosis-promoting effect of TRPC3 (Belkacemi et al., 2017).

The activation of TRPC channels causes $\mathrm{Na}^{+}$and $\mathrm{Ca}^{2+}$ influxes into the cell, leading to membrane depolarization and $\left[\mathrm{Ca}^{2+}\right]_{i}$ elevation. Both effects are important for TRPC channels to carry out their physiological functions. However, under conditions when these effects were not properly controlled, they can also contribute to pathology, reminiscent of iGluRs and other channels that damage cells through disrupting the membrane potential and/or causing $\mathrm{Ca}^{2+}$ overload. Due to differences in the biophysical properties, mechanisms of regulation, cell-type specific expression and subcellular distributions, the amplitudes, durations and subcellular locations of the depolarization and $\mathrm{Ca}^{2+}$ signals brought about by the activation of TRPC channels are likely very different from that by other channels. Furthermore, besides membrane depolarization and $\mathrm{Ca}^{2+}$ signals, TRPC channels also exert their effects on cell survival through other mechanisms, such as direct physical interactions with proteins involved in the cell death pathways (see later). Thus, the TRPC channels can have unique contributions to cell damage in difference diseases and different experimental models.

At least for TRPC4, a self-propagating positive-feedback mechanism has been proposed that allows persistent and prolonged channel activation (Thakur et al., 2020). In lateral septal neurons, this results in typically a depolarization plateau reaching to about $-5 \mathrm{mV}$ that lasts for about $1 \mathrm{~s}$ even when the stimulus, an agonist of mGluR1/5, is given for only $30 \mathrm{~ms}$ (Tian et al., 2014a). The all-or-none feature of the depolarization plateau is also consistent with the positive feedback mechanism. It was shown that this mechanism involves complex interactions among several intracellular messengers and protein partners, e.g., $\mathrm{Ca}^{2+}, \mathrm{H}^{+}$, and PLC $\delta 1$ (Thakur et al., 2020), the specific ranges of $\mathrm{Ca}^{2+}$ and $\mathrm{PIP}_{2}$ concentrations as well as the optimal 
membrane potentials required for channel activation (Thakur et al., 2016). The functional coupling with PLC $\delta 1$ is probably a major reason for the self-propagating activation of the TRPC4 channel, as the PLC isozyme is targeted by its own products, $\mathrm{Ca}^{2+}$ and $\mathrm{H}^{+}$(Thakur et al., 2020). PLC catalyzes the hydrolysis of $\mathrm{PIP}_{2}$, producing diacylglycerol (DAG), $\mathrm{IP}_{3}$ and $\mathrm{H}^{+}$(Huang et al., 2010). Subsequently, $\mathrm{IP}_{3}$ releases $\mathrm{Ca}^{2+}$ from the ER store through activation of $\mathrm{IP}_{3}$ receptors and depletion of the ER $\mathrm{Ca}^{2+}$ store is often accompanied with store-operated $\mathrm{Ca}^{2+}$ entry from the extracellular space (Putney, 2017). When coupled to TRPC4, $\mathrm{Ca}^{2+}$ influx through the TRPC4 channel also provides an additional source for greater and more prolonged $\left[\mathrm{Ca}^{2+}\right]_{i}$ increase, and the $\mathrm{Ca}^{2+}$ then feeds back to reinforce the activities of both PLC $\delta 1$ and TRPC4. In excitable cells, VGCCs also strongly impact native TRPC4 activation by bringing additional $\mathrm{Ca}^{2+}$, and perhaps also a part of the voltage sensitivity even though the TRPC channels are intrinsically voltage sensitive on their own (Gordienko and Zholos, 2004; Tian et al., 2014a). In addition, $\mathrm{PIP}_{2}$, which is continuously replenished upon hydrolysis through the actions of phosphatidylinositol 4 kinases and phosphatidylinositol-4-phosphate 5-kinases (Myeong et al., 2018), serves as both the membrane anchor and substrate of PLC 81 , as well as the source of DAG, $\mathrm{IP}_{3}$ and $\mathrm{H}^{+}$, which are all implicated in TRPC4 activation one way or the other (Storch et al., 2017; Thakur et al., 2020). However, at high concentrations, $\mathrm{PIP}_{2}$ also exerts a tonic block on TRPC4 activation (Otsuguro et al., 2008; Thakur et al., 2016), and similarly, high cytosolic $\mathrm{Ca}^{2+}$ concentrations also suppress the channel activity (Thakur et al., 2016, 2020). Moreover, the optimal membrane potentials for TRPC4 activation, especially native TRPC4-containing channels, have been observed at -40 to $-60 \mathrm{mV}$, and are influenced by $\left[\mathrm{Ca}^{2+}\right]_{i}$ (Gordienko and Zholos, 2004). Therefore, an intricate balance is created through complex interactions among $\mathrm{Ca}^{2+}, \mathrm{PIP}_{2}, \mathrm{DAG}, \mathrm{H}^{+}$, and membrane voltage to support the coupled activities of PLC $\delta 1$ and TRPC4, leading to sustained channel activity that lasts much longer than the time of exposure to the triggering stimuli. Notably, for TRPC4, the triggering stimuli include coincident activations of $\mathrm{G}_{i / o}$ proteins and PLC signaling through either $\mathrm{G}_{q / 11}$-PLC $\beta$ or receptor tyrosine kinase-PLC $\gamma$ pathways (Jeon et al., 2020). For other TRPC channels, $\mathrm{G}_{i / o}$ proteins may not be involved and the depolarization amplitude and duration may not be as strong and as long, respectively, as that of TRPC4. However, the dual (both stimulatory and inhibitory) regulation by $\mathrm{PIP}_{2}$ and $\mathrm{Ca}^{2+}$, and the sensitivity to DAG are common among the TRPCs (Wang et al., 2020), although whether or not they exhibit a specific dependence on a specific PLC isozyme, as in the case of PLC $\delta 1$ for TRPC4 (Thakur et al., 2016), remains to be elucidated. It is possible that other TRPC channels also exhibit self-propagating activation like TRPC4, but with different kinetics, amplitudes, and durations.

At the cellular level, the most direct evidence of TRPC channel contribution to cell death comes from cytotoxic effect of (-)englerin A, a guaiane sesquiterpenoid found in the bark of Phyllanthus engleri, on renal carcinoma cells (Akbulut et al., 2015; Carson et al., 2015) and triple-negative breast cancer (TNBC) cell lines (Grant et al., 2019) that express high levels of TRPC4 and/or TRPC1. It was found that englerin A exerts its cytotoxic effect through activation of TRPC4 and TRPC1/C4 channels endogenously expressed in the cancer cells. Intuitively, the cell killing action of englerin A was attributed to TRPC4-mediated $\mathrm{Ca}^{2+}$ influx and then intracellular $\mathrm{Ca}^{2+}$ overload, as $\mathrm{Ca}^{2+}$ overload by TRPC channels has indeed been reported to regulate apoptosis or other forms of programmed cell death in some cell types (Kondratskyi et al., 2015; Maher et al., 2018; Elzamzamy et al., 2020). However, a later study suggested that the cytotoxicity effect might largely result from the excessive $\mathrm{Na}^{+}$influx (Ludlow et al., 2017). It would appear that both the $\mathrm{Na}^{+}$and $\mathrm{Ca}^{2+}$ influxes mediated by TRPC channels are potentially harmful to the cell, if not properly controlled.

\section{THE ROLE OF TRPCS IN NEURODEGENERATIVE DISEASES ASIDE FROM STROKE}

Pathologically, excess glutamate accumulation is relevant to brain injury in many forms of neurodegenerative diseases. Therefore, before discussing the possible contributions of TRPC channels to brain injury associated with ischemic stroke, it is worthwhile to consider the involvement of TRPC channels in neuronal cell death in other neurodegenerative diseases, as they likely share some common mechanisms of excitotoxicity with ischemic stroke in damaging brain neurons. TRPC channels have been reported to play roles in a number of neurological disorders. Depending on the type of disease and the specific TRPC subtype, the activation of TRPC channels is not always detrimental to the neuron. Some TRPCs may actually be neuroprotective in certain neurodegenerative diseases.

A likely consequence of pathological accumulation of excess glutamate is coincident stimulation of both $\mathrm{G}_{q / 11^{-}}$and $\mathrm{G}_{i / 0^{-}}$ coupled mGluRs. This provides conditions for strong and prolonged self-propagating activation of TRPC4 and TRPC5 channels, leading to membrane potential disruption and $\mathrm{Ca}^{2+}$ overload. Indeed, TRPC1/C4 and TRPC5 channels have been implicated in seizure-induced neuronal death in mouse lateral septum and hippocampus, respectively, in the pilocarpineinduced model of epilepsy (Phelan et al., 2012). Inhibiting TRPC5 also protected neurons in pyriform cortex, amygdala, and hippocampus from death in kainate-treated rats with prolonged seizures (Park et al., 2019) and in hippocampal CA3 neurons in a tramatic brain injury model (Park et al., 2020). In these models, TRPC5 was thought to be activated by oxidation which first triggered a rise in cytosolic $\mathrm{Zn}^{2+}$ levels and then opening of TRPC5 channels to mediate $\mathrm{Ca}^{2+}$ influx, leading to neuronal cell death (Park et al., 2019). In the Huntington's disease model, activation of TRPC5 through glutathionylation has also been shown to cause the loss of striatal neurons (Hong et al., 2015), and this effect can be mitigated through destabilizing the presence of TRPC5 on plasma membrane via depalmitoylation (Hong et al., 2020).

On the other hand, TRPC4-containing channels are not always associated with neuronal cell injury. TRPC1/C4 heteromeric channels have been reported to exert a protective role in neuronal cell death induced by subarachnoid hemorrhage 
(Wang et al., 2016). This was suggested to occur through $\mathrm{Ca}^{2+}$ activation of calcineurin which suppresses NMDA receptor activity through dephosphorylation. Likewise, TRPC1 has been found to be neuroprotective in animal models of Parkinson's disease and Alzheimer's disease. In dopaminergic neurons of substantia nigra, TRPC1 inhibits L-type VGCCs by facilitating the interaction of STIM1 with Cav1.3 in response to $\mathrm{ER} \mathrm{Ca}^{2+}$ store depletion and thereby dampening the neurotoxin-induced VGCC function that causes neuronal death (Sun et al., 2017). In addition, through store-operated $\mathrm{Ca}^{2+}$ entry, TRPC1 protects the dopaminergic neurons from neurotoxin-induced ER stress and the decrease of AKT/mTOR signaling (Selvaraj et al., 2012). Conversely, dopaminergic neurons respond to neurotoxin with decreased store-operated $\mathrm{Ca}^{2+}$ entry via attenuation of TRPC1 transcription, which is regulated by NF- $\kappa$ B (Sukumaran et al., 2018). Furthermore, the inhibition of TRPC1-mediated $\mathrm{Ca}^{2+}$ entry by neurotoxin is facilitated by sigma 1 receptor, an ER membrane protein acting as a chaperone to regulate $\mathrm{Ca}^{2+}$ release and other functions, which ultimately leads to the loss of dopaminergic neurons (Sun et al., 2020). In the mouse model of Alzheimer's disease, the deletion of trpc1 gene was found to aggravate amyloid- $\beta$ (A $\beta$ )-induced learning and memory deficits and TRPC1 was shown to interact with $A \beta$ precursor protein (APP) at the transmembrane region, resulting in reduced $A \beta$ levels in hippocampal neurons and attenuation of apoptosis ( $\mathrm{Li}$ et al., 2018). By contrast, the upregulated TRPC1 expression seen in SK-N-SH human neuroblastoma cells expressing a polyglutamine Huntingtin mutant was found to support a store-operated non-selective cation current and this activity contributed to glutamate-induced apoptosis of primary cultured striatal medium spiny neurons prepared from YAC128 mice that mimic neurodegeneration of Huntington's disease (Wu et al., 2011). Indeed, eliminating TRPC1 in YAC128 mice improved motor performance and rescued neuronal spines from progressive loss (Wu et al., 2018). Therefore, TRPC1 may be either detrimental or beneficial to brain neurons depending on the models and neuronal cell types.

TRPC3 has been speculated to play a part in ischemic injury of the cerebellum owning to it higher expression in this than in other brain regions (Cederholm et al., 2019). However, this regional specific effect of TRPC3 was found to change in aging monkeys and transgenic mice overexpressing human $\alpha$-synuclein, where TRPC3 was found to become enriched in the mitochondria of striatal neurons and contribute to the disruption of mitochondrial membrane potential and cell apoptosis commonly seen in Parkinson's disease (Chen M. et al., 2017). Thus far, TRPC3 represents the only TRPC isoform that has been localized to mitochondria, in addition to its common plasma membrane localization, and involved in $\mathrm{Ca}^{2+}$ uptake into the organelle (Feng et al., 2013). Thus, the link of TRPC3 expression and function in mitochondria to $\alpha$-synuclein upregulation implicates a role of TRPC3 in the pathogenesis of Parkinson's disease (Chen M. et al., 2017). In a rodent model of pilocarpine-induced status epilepticus, while the expression of TRPC3 was found to be increased, that of TRPC6 was decreased in CA1 and CA3 pyramidal neurons and dentate granule cells. It was reported that either inhibiting TRPC3 or enhancing TRPC6 function and/or expression protected neurons from seizureinduced injury (Kim et al., 2013). These findings support the detrimental effect of TRPC3 hyperactivation on brain neurons, but implicate that TRPC6 may exert an opposite effect.

Indeed, although closely related to TRPC3, TRPC6 has mainly been shown to be protective against neurodegeneration. For example, a system wide reduction of TRPC6 expression was found in patients with Alzheimer's disease and mild cognitive impairment, including blood cells, which negatively correlated with the cognitive performance (Lu et al., 2018; Chen et al., 2019). Moreover, neurons differentiated from induced pluripotent stem cells (iPSCs) derived from peripheral blood of sporadic Alzheimer's disease patients also exhibit decreased TRPC6 expression, as well as elevated A $\beta$ and phosphorylated tau levels, hallmarks of Alzheimer's disease (Tao et al., 2020). Mechanistically, TRPC6 has been proposed to physically interact with APP via its second transmembrane segment, through which it inhibits the cleavage of APP by $\gamma$-secretase, leading to reduced $A \beta$ production (Wang et al., 2015). That increasing TRPC6 expression or using a membrane penetrating peptide representing TRPC6's second transmembrane segment effectively lowered the levels of $A \beta$ and phosphorylated tau in iPSC neurons derived from sporadic Alzheimer's disease patients supports a role of TRPC6 in suppressing the disease pathogenesis (Tao et al., 2020).

In a separate study, TRPC6 was found to form a complex with Orai2 that is regulated by STIM2 to conduct store-operated $\mathrm{Ca}^{2+}$ influx in dendritic mushroom spines of hippocampal neurons (Zhang et al., 2016). When this is impaired, the mushroom spines become unstable and disrupted, leading to memory loss. The beneficial effect of TRPC6 to Alzheimer's disease was demonstrated by showing that stimulating TRPC6 or the store-operated $\mathrm{Ca}^{2+}$ entry improved hippocampal longterm potentiation of the APP-presenilin 1 mutant mice, an experimental model of Alzheimer's disease (Zhang et al., 2016; Popugaeva et al., 2019). However, in a different model, where the expression of a familial Alzheimer's disease (FAD) presenilin 1 mutation bearing the deletion of the 9th exon (PSEN1 $\triangle \mathrm{E} 9$ ) in hippocampal neurons caused mushroom spine loss through enhancing, instead of suppressing, TRPC6-mediated storeoperated $\mathrm{Ca}^{2+}$ entry, inhibiting such activity then becomes beneficial (Chernyuk et al., 2019). Therefore, depending on the nature of dysregulation, TRPC6 can be either beneficial or detrimental to neurons, highlighting the importance of maintaining the proper $\mathrm{Ca}^{2+}$ homeostasis. Previously, an inhibitory effect of presenilin 2 and its Alzheimer's-diseaselinked variants on receptor-operated TRPC6 function has been demonstrated in heterologous expression systems, suggesting functional interaction between presenilins and TRPC6 (Lessard et al., 2005). In status epilepticus, TRPC6 serves to protect granule neurons of dentate gyrus from degeneration through activation of ERK1/2 and the subsequent phosphorylation of dynaminrelated proteins 1 (DRP1) at Ser-616 (Ko and Kang, 2017) and an increase in the expression of a mitochondrial protease, Lon protease-1 (Kim et al., 2019). In the absence of TRPC6, the hypo-phosphorylation of DRP1 and reduction in Lon protease1 then lead to mitochondrial elongation and dysfunction, which 
increase the vulnerability of granule cells to seizure-induced death (Kim and Kang, 2015).

Taken together, the above findings suggest that TRPC channels exert differential effects on neurodegeneration in isoform and disease specific fashions. Although $\left[\mathrm{Ca}^{2+}\right]_{i}$ dysregulation and membrane depolarization may be the common effects of TRPC channel activation, other mechanisms, including protein-protein interactions that involve specific regions of particular TRPC subtypes with certain disease-related protein partners and unique signaling pathways pertaining to the regulation of specific TRPC channels, are also involved. These diverse mechanisms underlie the differential outcomes resulting from TRPC channel function, ranging from neuroprotection to neurodegeneration. Therefore, it cannot be generalized that the extended activation of TRPC channels always leads to cell death, despite the high risk of $\mathrm{Ca}^{2+}$ overload.

\section{THE ROLE OF TRPCS IN ISCHEMIC BRAIN INJURY}

Brain injury after focal ischemic insult has been linked to the reduction of oxygen and nutrient (glucose) supply to the affected brain region (Lipton, 1999; Lo et al., 2003). Both in vivo MCAO model and the in vitro OGD model are commonly used to evaluate the involvement and mechanisms of TRPC channels in neuronal cell death associated with ischemic stroke. Like with the other neurodegenerative diseases discussed above, these studies revealed complex roles of different TRPC channels in ischemic brain injury.

For TRPC1, both the MCAO model and OGD assay suggested that TRPC1 plays a protective role against neuronal injuries caused by cerebral ischemia/reperfusion through suppression of ROS generation (Xu et al., 2018). TRPC1 expression was shown to be downregulated not only in brain tissues of mice subject to $90 \mathrm{~min}$ MCAO followed by $24 \mathrm{~h}$ reperfusion, but also in the cultured murine hippocampal cell line, HT22, that was exposed to an OGD culture for $4 \mathrm{~h}$ and then placed in the reoxygenated normal medium for 6-24 h. It was demonstrated that the amplitude of store-operated $\mathrm{Ca}^{2+}$ entry in the hippocampal cells was positively corrected with the expression TRPC1, but negatively correlated with the NADPH oxidase activity, and unrelated to the expression of STIM1 and Orail as well as mitochondrial ROS generation. However, no evidence was provided to suggest a direct inhibitory effect of $\mathrm{Ca}^{2+}$ on NADPH oxidase activity. Rather, TRPC1 inhibited NADPH oxidasemediated ROS production through physically interacting with a catalytic component of the oxidase, Nox4, which facilitated Nox4 degradation along with cytoplasmic retention of the cytosolic subunits of the NADPH oxidase complex, p47phox and p67phox (Xu et al., 2018). This protective role of TRPC1 is opposite from the results of an earlier work, which showed that SKF96365 prevented cortical neuron death induced by $1.5 \mathrm{~h}$ OGD and $24 \mathrm{~h}$ reoxygenation (Wang et al., 2016). Since SKF96365 is a nonspecific drug that inhibits all TRPC channels, and all forms of store- and receptor-operated $\mathrm{Ca}^{2+}$ entry, it did not inform which specific channel type was responsible for the protective effect.
On the other hand, the TRPC3/6/7 triple knockout mice were reported to be resistant to brain injury induced by MCAO followed by reperfusion (Chen X. et al., 2017). Here, the detrimental role of TRPC $3 / 6 / 7$ channels was attributed at least in part to astrocytes, in which these channels contributed to the enhanced NF- $\mathrm{KB}$ phosphorylation, reduced AKT phosphorylation and increased cell apoptosis following OGD and reoxygenation treatment (Chen X. et al., 2017). How this function of TRPC $3 / 6 / 7$, which promotes the death of astrocytes, is related or coordinated with astrogliosis, an abnormal proliferation of brain astrocytes observed after stroke and shown to be positively regulated by TRPC3 (Shirakawa et al., 2010; Munakata et al., 2013; Belkacemi et al., 2017), is an interesting question that needs to be addressed in future studies.

Although TRPC6 expression in mouse cortical neurons has been reported to be increased following brain ischemia/reperfusion in vivo and $\mathrm{OGD} /$ reoxygenation in vitro, and this increase contributed to neuronal injury in an NMDA receptor-dependent manner (Chen J. et al., 2017), nearly all other studies argue for a protective role of TRPC6 in neurological damage associated with ischemic stroke. The neuroprotective role of TRPC6 was suggested to occur through activation of cAMP response element-binding protein (CREB) signaling, which is disrupted following cerebral ischemia due to degradation of TRPC6 proteins in neurons by proteolytic cleavage mediated by calpain, non-lysosomal cysteine proteases activated as a result of $\left[\mathrm{Ca}^{2+}\right]_{i}$ rise from NMDA receptor activation by elevated extracellular glutamate (Du et al., 2010). It was found that attenuating the calpain-mediated TRPC6 degradation could underlie the neuroprotective effects of several natural compounds, such as resveratrol, neuroprotectin D1, and (-)-epigallocatechin-3-gallate (the main ingredient of green tea), and calycosin (Lin et al., 2013a; Yao et al., 2013, 2014; Guo et al., 2017). That these protective effects were obliviated by inhibiting mitogen-activated protein kinase kinase (MEK) and/or calmodulin kinases suggests that these kinases mediate CREB activation downstream from TRPC6 (Lin et al., 2013b; Yao et al., 2013). On the other hand, increasing TRPC6 expression or its function through overexpression or treatment with hyperforin also inhibited NMDA receptor function and suppressed calpain activity (Li et al., 2012; Lin et al., 2013b), indicative of reciprocal regulations between TRPC6 and NMDA receptors/calpain. Once suggested as a TRPC6 agonist (Leuner et al., 2007), hyperforin was found to increase TRPC6 expression in mouse hippocampus following ischemia/reperfusion (Lin et al., 2013b). Hyperforin was also reported not to change TRPC6 channel activity, but acts independently of TRPC6 as a protonophore, which may explain its anti-depressive effects (Sell et al., 2014). Furthermore, the calpain cleavage of TRPC6 has also been reported to be activated by interleukin 17 (IL-17) (Zhang et al., 2014), a T-cell derived pro-inflammatory cytokine shown to contribute to ischemic brain injury (Gelderblom et al., 2012), suggesting an immuneneural interaction that exacerbates ischemic neurological damage through downregulating TRPC6.

In contrast to the rich information on TRPC6, little is known about the roles of TRPC4 and TRPC5 in brain injury associated with ischemic stroke. In one study, it was reported that TRPC4 
protein expression was increased in rat striatal and hippocampal neurons at $12 \mathrm{~h}$ to 3 days after MCAO (Gao et al., 2004). Other studies speculating a detrimental function of TRPC5 in neurological deficits following stroke had based on the activation of TRPC5 by oxidation, without experimentation in the stroke model (Ishii et al., 2011; Park et al., 2019, 2020). In a very recent study, TRPC5 was found to directly interact with phospholipid scramblase 1 (PLSCR1) on the plasma membrane to facilitate externalization of phosphatidylserine (PS) and apoptosis of cortical neurons in response to cerebral ischemia/reperfusion (Guo et al., 2020). The same protein complex likely also includes TRPC1 and TRPC4. While the examination of cerebral slices of animals subject to ischemia/reperfusion revealed reduced PS externalization and apoptosis in TRPC5 knockout mice, whether these translate into protection against cerebral infarction and/or behavioral neurological impairments remains to be elucidated (Guo et al., 2020). On the other hand, overexpression of TRPC5 in spinal cord via adeno-associated viruses attenuated spinal cord ischemia/reperfusion injury in rats (Shen et al., 2020). This could result from the angiogenic function of TRPC5 which dampens the injury induced inflammation. Indeed, TRPC5 has been reported to promote endothelial cell sprouting, angiogenesis, and blood perfusion in ischemic tissues through activation of nuclear factor of activated T cell (NFAT) isoform c3 and angiopoietin-1 (Zhu et al., 2019). Therefore, the effect of TRPC4/C5 on ischemic brain injury may be very complex, including both positive and negative regulations that either exacerbate or prevent neuronal cell death.

\section{TRPC4 IN ISCHEMIC BRAIN INJURY - OUR OWN STUDY}

The above analysis indicates that despite the common mechanisms that link G protein and PLC pathways to TRPC channel activation and the likelihood that these channels participate in excitotoxicity triggered by excessive extracellular accumulation of glutamate through mGluRs, it is not easy to predict whether a specific TRPC channel type is detrimental or beneficial to brain neurons under conditions of cerebral ischemia/reperfusion. Depending on the TRPC isoforms, cell types involved, and mechanisms of actions, the TRPC channel may be neuroprotective or destructive.

To define the overall contributions of TRPC channels in brain damage associated with cerebral ischemia, we first compared neurological scores and brain infarction volumes of wild type and quadruple TRPC1, C4, C5, C6 knockout (QuadKO) mice subject to $40 \mathrm{~min}$ of MCAO using the standard intraluminal suture (thread) method, followed by $24 \mathrm{~h}$ reperfusion. In this method, a monofilament nylon surgical suture with a heat-rounded tip is inserted from an opening at external carotid artery and advanced through internal carotid artery until it reaches the middle cerebral artery to block the blood flow there. After the desired time period of occlusion, the filament was withdrawn to allow resupply of the blood to the blocked brain area (Alkayed et al., 1998; Sun et al., 2019). Since TRPC2 is mainly expressed in the vomeronasal system (Liman et al., 1999), TRPC3 mainly present in the cerebellum (Hartmann et al., 2008), and TRPC7 mostly found in peripheral tissues (Okada et al., 1999), we consider TRPC1, C4, C5, and C6 as the main cerebral TRPC subtypes expressed in areas typically affected in the MCAO model. As described above, both TRPC1 and C6 have been suggested to play protective roles against ischemic brain injury, but the function of TRPC4 and C5 remains unclear. Therefore, the QuadKO mice provide a good model to learn if TRPC channels generally serve a protective or detrimental role in cerebral ischemia. We found that on average, TRPC-QuadKO mice had better neurological scores (Figure 2A) and smaller brain infarct areas (shown by staining with 2,3,5-triphenyltetrazolium chloride, TTC) than the wild type mice (Figures 2B,C), suggesting that overall, TRPC channels contribute to causing damage of the brain in response to cerebral ischemia/reperfusion. Given that TRPC1 and TRPC6 may play some neuroprotective function during ischemia/reperfusion, it is plausible that the detrimental actions are mainly mediated by TRPC4 and/or TRPC5, and these two TRPC isoforms may dominate the cortical neuronal responses to ischemic insults. This interpretation is consistent with the finding that TRPC4/C5 expression is more abundant than other TRPC isoforms in several major areas of rat brain, including the prefrontal cortex (Fowler et al., 2007). Clearly, the distinct contributions of different TRPC isoforms in brain injury at different stages of cerebral ischemia/reperfusion warrant more detailed investigation.

Given that among the major brain TRPC isoforms, only TRPC4 has not been evaluated for its role in ischemic stroke, we then set out to compare brain damages caused by cerebral ischemia/reperfusion in wild type and TRPC4 knockout mice. Here, we performed transient focal middle cerebral artery/common carotid artery occlusion (MCA/CCAO) on the animals for 30, 90, and $120 \mathrm{~min}$, followed by $24 \mathrm{~h}$ reperfusion. The MCA/CCAO is surgically performed using craniotomy to directly occlude distal MCA with a thin stainless wire (Aronowski et al., 1994; Zhao et al., 2015). This type of method was reported to produce reversible infarction and confined focal cerebral ischemia at distal MCA territory (Braeuninger and Kleinschnitz, 2009; Tavafoghi et al., 2016). We found that the infarct areas were markedly smaller in brains of $\operatorname{Trpc} 4^{-/-}$ mice than wild type animals, especially with shorter time of ischemia, i.e., 30 and 90 min (Figures 2D,E). Specifically, with the $30 \mathrm{~min}$ ischemia followed by $24 \mathrm{~h}$ reperfusion, whereas the infarctions were readily visible in wild type brains, they were hardly detectable in Trpc4 $4^{-/}$specimens. However, with a longer time (120 min) ischemia, the protective effect of TRPC4 knockout diminished (Figures 2D,E). These data indicate that TRPC4containing channels contribute positively to ischemic brain damage, particularly during the early time period of the ischemia.

Next and to attribute underlying mechanisms more directly to TRPC4 function in neurons, we used cortical neuron cultures prepared from newborn wild type, $\operatorname{Tr} p c 1^{-/-}, \operatorname{Tr} p c 4^{-/-}$ and TRPC QuadKO mice to examine the effect of OGDreoxygenation on cultured neurons in vitro (Ying et al., 1997). As illustrated in Figure 3A, cells were cultured for 16-18 days in vitro (DIV). On the day of the experiment, the culture medium was replaced with either a deoxygenated bicarbonate buffer without glucose (OGD) or an oxygenated bicarbonate 

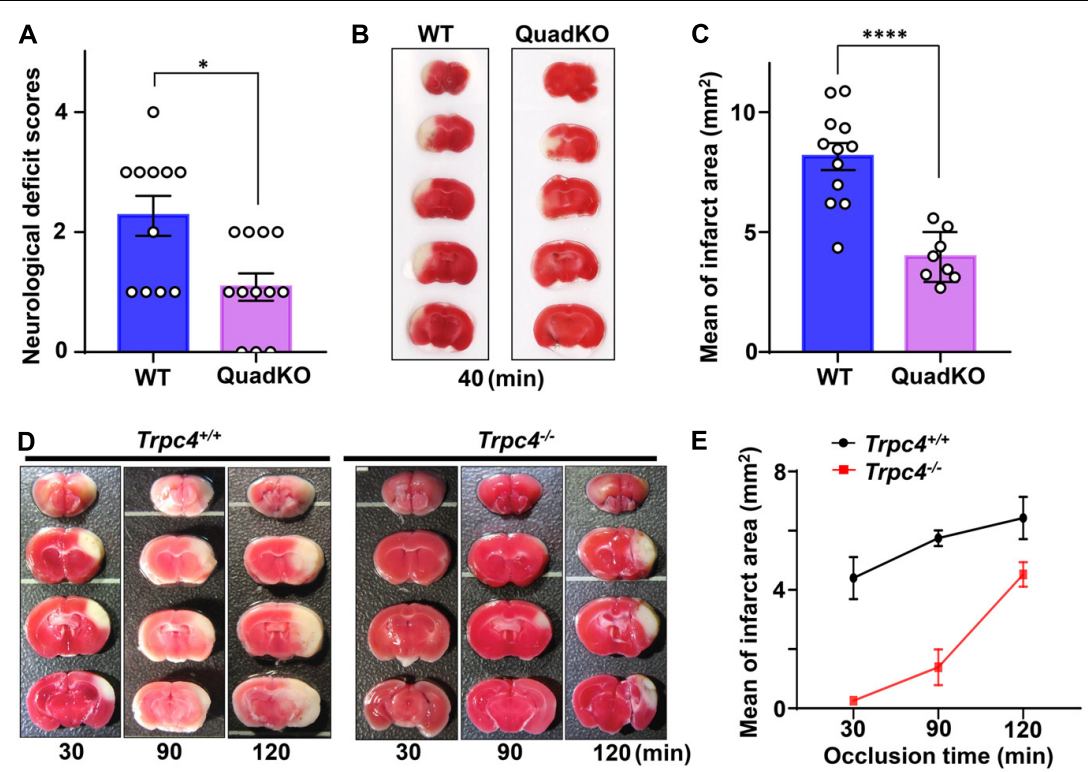

FIGURE 2 | Transient receptor potential canonical (TRPC) deficiency attenuates cerebral ischemic damage. (A-C) TRPC1, C4, C5, C6 quadruple knockout (QuadKO) and wild type control mice were subjected to reversible MCAO for 40 min using intraluminal suture method, followed by $22-24 \mathrm{~h}$ reperfusion. After assessing neurological deficits as described (Li et al., 2011) (A), the animals were sacrificed and brain sections stained with TTC for quantification of infarct areas (B,C). (A) Neurological scores of animals subjected to ischemia/reperfusion. Data represent means $\pm \mathrm{SEM}$ for $n=11$ (wild type) and 12 (QuadKO) mice. ${ }^{*} P<0.05$ by Mann-Whitney test. (B) Representative photographs of TTC-stained brain sections demarcating infarction. (C) Infarct areas at rostrocaudal plains were determined from morphometric analyses of TTC-stained brain sections. Data represent means \pm SEM for $n=12$ (wild type) and 8 (QuadKO) mice. **** $P<0.0001$ by unpaired $t$-test. (D,E) Trpc4-/- and wild type control mice were subjected to reversible 30, 90, and 120 min MCA/CCAO, followed by 24 h reperfusion. (D) Representative photographs of TTC-stained brain sections. (E) Infarct areas at rostrocaudal plains were determined from morphometric analyses of TTC-stained brain sections. Data are presented as means \pm range for $n=2$ mice for each time point.

buffer with glucose (Control), and the cultures were maintained in a $37^{\circ} \mathrm{C}$ hypoxic incubator for $2 \mathrm{~h}$ with the oxygen level kept at $1 \%$ atmosphere. After the treatment, the neurons were either immediately evaluated for cell death by staining with propidium iodide (PI) or returned to the normal culture medium and maintained in the regular incubator at the normal oxygen level for $24 \mathrm{~h}$ before the PI staining. All cells were also stained with DAPI (4',6-diamidino-2-phenylindole) to label the nuclei (Figure 3B). A comparison of the ratios of PI-positive/DAPIpositive labels, which represent percental cell death, revealed that wild type neurons were more vulnerable than the TRPC knockout neurons to the $2 \mathrm{~h}$ exposure of the bicarbonate buffer no matter if the buffer was oxygenated or not (Figure 3C). The reason for this is unclear, but could be related to the differences in the developmental status between the wild type and TRPC knockout cortical neurons cultured in vitro. Indeed, TRPCs play roles in several different aspects of neuronal development (Greka et al., 2003; Jeon et al., 2013; Tian et al., 2014b) and some of these could influence the sensitivity of the neurons to nutrient deprivation, given that the bicarbonate buffer does not contain serum and amino acids. This protective effect of TRPC depletion on neuronal survival in the serum and amino acid-deprived but glucose-containing buffer requires further investigation. Despite this, while the 2-h OGD treatment (without reoxygenation) did not immediately increase cell death further in wild type cortical neurons, it did so in all TRPC knockout neurons (Figure 3C), suggesting that OGD may interfere with the protective effect of
TRPC knockout on cultured cortical neurons subject to serum and amino acid deprivation.

With the $24 \mathrm{~h}$ reoxygenation and nutrient replenishment (herein referred to as refeeding), cell death nearly doubled in wild type neurons that had been treated with OGD but not those exposed to the control buffer. The response to refeeding, however, was quite different between the three different TRPC knockout lines. The control buffer-treat QuadKO neurons displayed a marked increase in cell death after $24 \mathrm{~h}$ refeeding, but OGDtreated ones virtually did not change. However, while the $\operatorname{Tr} p c 1^{-/-}$neurons did not show any increase in death after refeeding regardless of the oxygen and glucose status during the starvation, the $\operatorname{Tr} p c 4^{-/-}$neurons exhibited a marked refeedingdependent increase in cell death only when OGD treatment was applied (Figure 3C). These results, although difficult to interpret without more extensive investigations, underscore the complex and diverse roles different TRPC channels play in neuronal cell responses to nutrient shortage, OGD, and the subsequent replenishment of all nutrients, including oxygen.

To avoid the complications with the cultured neurons and the developmental effects of the TRPC knockout, we also performed OGD experiments using brain slices following a previous protocol (Taylor et al., 1999; Tasca et al., 2015). As illustrated in Figure 4A, the cerebral slices from wild type mice were recovered in artificial cerebrospinal fluid (aCSF) bubbled with $95 \% \mathrm{O}_{2}$ and $5 \% \mathrm{CO}_{2}$ at $35^{\circ} \mathrm{C}$ for $1-2 \mathrm{~h}$ after cutting. Then they were transferred to a modified aCSF omitting glucose 
A Experimental timeline

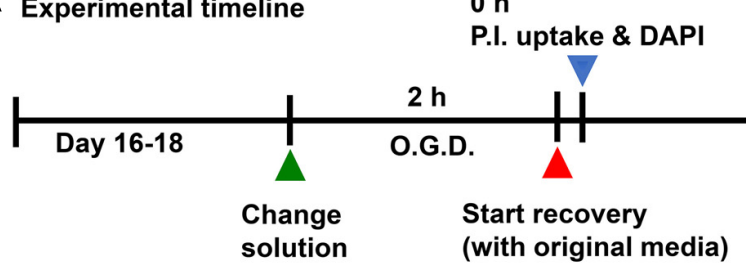

B
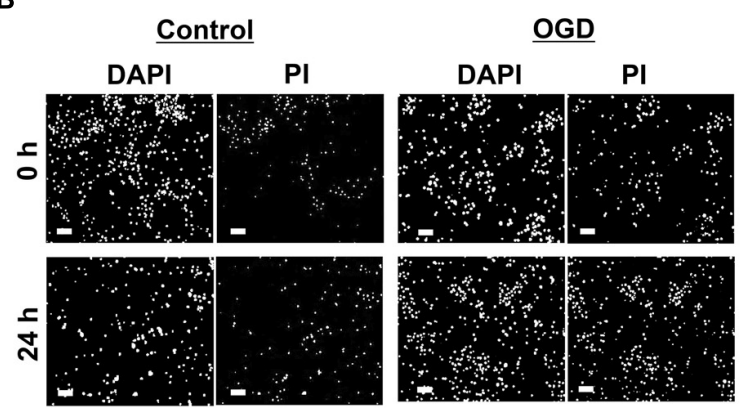

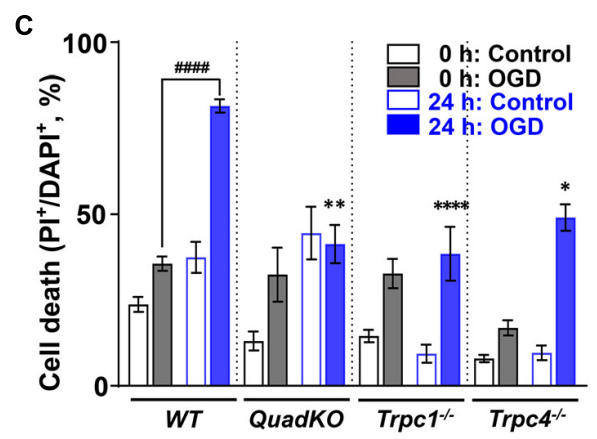

FIGURE 3 | Oxygen and glucose deprivation (OGD)-induced cell death of cultured cortical neurons from wild type, Trpc1 $1^{-/-}$, Trpc $4^{-/-}$, and Trpc1/c4/c5/c6 $6^{-/-}$ mice. (A) Schematic of the experimental timeline. Primary cultures of cortical neurons (16-18 DIV) from WT, Trpc1-/-, Trpc4-/-, and Trpc1/c4/c5/c6-/- (QuadKO) mice were treated without or with OGD for $2 \mathrm{~h}$ and then allowed to grow in normal medium for 0 or $24 \mathrm{~h}$. (B) Representative images of DAPI staining (Bocksch et al., 2010) and PI uptake of cultured cortical neurons from wild type (WT) mice grown under control conditions or subjected to OGD for $2 \mathrm{~h}$. Cells were stained either immediately after the treatment $(0 \mathrm{~h})$ or returned to normal culture conditions for $24 \mathrm{~h}$ before staining $(24 \mathrm{~h})$. Scale bars, $50 \mu \mathrm{m}$. (C) Summary data of PI-positive cells, normalized to the total cell number determined by DAPI staining. Data represent means \pm SEM of $n=20$ to 30 fields of views for each condition pooled from 4 coverslips of neurons from two separately prepared primary cultures. ${ }^{\# \# \# ~} P<0.0001,{ }^{*} P<0.05,{ }^{* *} P<0.01,{ }^{* * * *} P<0.0001$ vs. WT 24 h: OGD by one-way ANOVA.

and bubbled with $\mathrm{N}_{2}$ (OGD) and maintained for $30 \mathrm{~min}$ at the same temperature. Control slices were treated with fresh oxygenated aCSF in parallel. After that, all slices were returned to fresh oxygenated aCSF and incubated for another $3 \mathrm{~h}$. PI and Hoechst were added at 40 and $10 \mathrm{~min}$, respectively, before the end of the incubation to label dead cells and nuclei of all cells. This was followed by fixation with $4 \%$ paraformaldehyde $\left(12 \mathrm{~h}\right.$ at $4^{\circ} \mathrm{C}$ ) and mounting. In order to examine to what extent inhibiting TRPC4/C5 channels can protect against OGDinduced neuronal death and the possible therapeutic windows of targeting these channels, we also applied TRPC4/C5 antagonists, ML204 (Miller et al., 2011) and compounds 9 and 13 (cpd 9, cpd 13, analogs of M084) (Zhu et al., 2015), either at the beginning or the end of the OGD treatment. As shown in Figures $4 \mathrm{~B}, \mathrm{C}$, after $30 \mathrm{~min} \mathrm{OGD}$ and $3 \mathrm{~h}$ reoxygenation, the number and intensity of PI labeling in the cortex area were dramatically increased as compared to the control. Including the TRPC4/C5 antagonists either during or post OGD significantly decreased the damage. Since the TRPC4/C5 antagonists inhibit both TRPC4 or TRPC5 homomeric channels and TRPC1/C4 and TRPC1/C5 heteromeric channels, these data support the general idea that targeting TRPC1/C4/C5 channels can be beneficial to stroke therapy including post ischemic protection. Clearly, additional studies are needed to illustrate the details on how these TRPC channels contribute to neurological damage in response to ischemia and reperfusion and the appropriate intervention strategies that bring the most benefit with minimal detrimental effects.

\section{DISCUSSION}

Recent studies have demonstrated that TRPC channels play complex and even opposing functions in neuronal cell survival and death. Depending on the different TRPC subtypes, brain locations and cell types, as well as the specific pathological conditions, TRPC channels can be either detrimental or beneficial to neurons. However, the general theme is that for nearly every neurodegenerative disease, TRPC channels play crucial roles, and these include ischemic stroke and other conditions that cause brain injury. Because of the diverse mechanisms that have been revealed so far, it is also clear that no generalized mechanism should be used to explain or predict how a specific TRPC channel contributes to brain injury. Even for TRPC6, although most studies have indicated a pro-survival role, the molecular and cellular mechanisms elucidated from various studies have been very different, ranging from a direct interaction of the channel with a specific disease-causing protein (Wang et al., 2015), regulation of mitochondrial fission (Ko and Kang, 2017), to CREB-dependent transcription (Du et al., 2010) and suppression of NMDA receptor and calpain function (Li et al., 2012; Lin et al., 2013b). Therefore, future studies should focus not only on unique mechanism(s) that underlies the regulation of a specific TRPC channel in a particular form of neuronal injury, but also make attempts to reconcile the mechanism with existing knowledge and identify a common theme(s), if possible, that would enrich the mechanistic understanding of how the TRPC channel contributes to disease pathogenesis. 

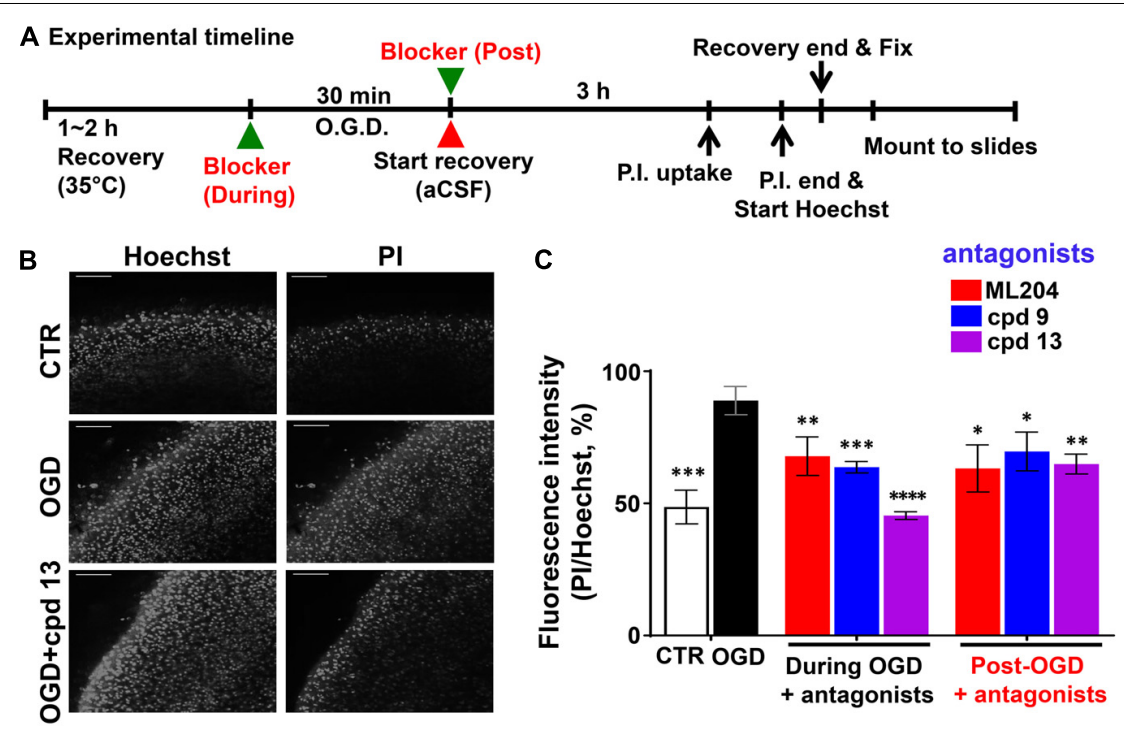

FIGURE 4 | Oxygen and glucose deprivation -induced neuronal death in the cerebral cortex of mouse brain slices. TRPC4/C5 blockers rescued OGD-induced neuronal death in the cerebral cortex of brain slices. (A) Schematic of the experimental timeline. (B) Representative images of Hoechst staining (left panels) and PI uptake (right panels) of acute brain slices (P15) from wild type (WT) mice without (CTR) or with OGD for 30 min in the absence or presence of TRPC4/C5 blocker, compound 13 (cpd 13). After the treatment, the slices were recovered for $3 \mathrm{~h}$ and stained with PI and Hoechst at 40 and 10 min, respectively, before the end of the $3 \mathrm{hr}$ incubation. Scale bars, $100 \mu \mathrm{m}$. (C) Summary data of Pl/Hoechst fluorescence ratios (random unit, but the same settings used for all conditions). TRPC4/C5 blockers, ML204 (at $50 \mu \mathrm{M}$ ), cpd 9, and cpd 13 (at $30 \mu \mathrm{M}$ ) prevented the OGD-induced cell death to varying degrees no matter if they were added during or after (post) the OGD treatment. Data represent means \pm SEM of $n=8$ to 15 fields of view of independently treated slices. ${ }^{*} P<0.05,{ }^{* *} P<0.01,{ }^{* * *} P<0.001$,

**** $P<0.0001$ vs. OGD without antagonist by Student $t$-test.

Particularly for brain damage associated with ischemic stroke, the roles of TRPC channels at different stages of the ischemia/reperfusion and in different brain areas are far from clear. The acute deprivation of oxygen and glucose, as well as other nutrient supplies, certainly exerts a tremendous stress on neurons, causing many changes in signal transduction and intracellular and extracellular messengers that are linked to TRPC channels through either functional or physical coupling or both. These can be factors that directly activate the channel, such as DAG or ROS, or transmitters that work through G proteincoupled receptors, like glutamate, as well as neurotrophic factors that stimulate tyrosine kinases, e.g., BDNF. The combination of some of these factors may even bring synergistic effect, making some otherwise insignificant molecules into important contributors to TRPC channel activation that either induces neuronal death or protects them from the damages caused by other signals. Importantly, changes that occur in the ischemic stage do not just revert back to their original states after reperfusion or oxygenation. The restoration of nutrient supply and blood circulation also causes inflammation and oxidation, leading to stress responses that may evoke TRPC activation as well. Thus, a TRPC subtype may be involved in either the ischemic or reperfusion stage, or both stages, of the ischemia/reperfusion injury but with different outcomes. Furthermore, while irreversible damages can occur immediately at the ischemic core during OGD through necrosis, neurons in the neighboring regions (ischemic penumbra) more often display delayed cell death or apoptosis (Rami and Kogel, 2008). It is not known how different TRPC isoforms are involved in the different forms of cell death pathways, and therefore, it remains to be elucidated whether and how each of them plays a part in different stages and different brain regions (core $v s$. penumbra) in neurological damages associated with ischemia/reperfusion. These, together with the diverse mechanisms that have been reported for TRPC channel activation under pathological conditions, argue for the need of more careful and systematic examinations of TRPC channels in ischemic brain damage.

In practice, a stroke therapy is more useful in post-stroke than during or pre-stroke application since in most cases, the need for treatment is only realized after the stroke has occurred. Therefore, a better understanding of mechanisms that contribute to neuronal death during reperfusion and/or in ischemic penumbra instead of the core area, or any intervention that would facilitate the recovery of damaged neurons, if possible, from the death pathway will be desirable for therapeutic development. However, despite all the studies that have been discussed above, nothing is available on whether any TRPC channel would be a good target of post-stroke neuroprotection. Our in vitro experiment (Figure 4) suggests that it might be possible for the TRPC4/C5 inhibitors to have such a function, even though it might not be a complete protection. It may be common that targeting a single pathway or molecule post-stroke or post-OGD will not completely protect all neurons from ischemic injury, since even if the targeting is effective and represents the most critical one, irreversible damages that have occurred during ischemia will unlikely be rescued. Recently, the TRPC channel field has experienced an explosion of newly identified small molecular probes that can act as either selective agonists or antagonists of specific TRPC 
channel subtypes (Wang et al., 2020). This gives an opportunity to test whether selectively enhancing or suppressing the function of a specific TRPC subtype at different time points post MCAO will exacerbate or inhibit brain damage and neurological deficits. Of course, these experiments will need to be followed by cell type specific manipulation of TRPC channel function or expression and other approaches in order to gain mechanistic insights on how the channel contributes to the delayed neuronal death.

Mechanistically, even though $\mathrm{Ca}^{2+}$ signal is an obvious downstream event of TRPC channel activation, there can be many different kinds of consequences which may or may not be related to the $\mathrm{Ca}^{2+}$ signal. The downstream targets of $\mathrm{Ca}^{2+}$ also remain largely undefined, although both CaMKII and calcineurin have been implicated. $\mathrm{Ca}^{2+}$-dependent kinases could also include those that phosphorylate NMDA receptor NR2B subunits, e.g., DAPK1, which is known to play a role in stroke (Nair et al., 2013). TRPC channels can mediate DAPK1 activation through calcineurin or calmodulin (Shamloo et al., 2005; Nair et al., 2013). Also, as has been illustrated for TRPC6, calpain is another possible candidate of $\mathrm{Ca}^{2+}$ regulation and it is known to play a role in NMDA receptor-mediated cell death (Lankiewicz et al., 2000; Simpkins et al., 2003). Therefore, specific inhibitors of the above $\mathrm{Ca}^{2+}$-regulated enzymes, calpain, CaMKII, calcineurin, and DAPK1 may be used to dissect their roles.

In summary, although TRPC channels appear to be ideally suited for integrating mGluR signaling to contribute to excitotoxicity to neurons under conditions of ischemic stroke, critical data demonstrating their involvement in neuronal damage or protection are only beginning to emerge. The pathological significance and roles of TRPC channels in ischemia/reperfusion remain to be fully elucidated. More detailed studies on regulatory mechanisms of TRPC channels will also shed lights on their functional significance in stroke pathology and future drug development.

\section{METHODS}

\section{Animals}

All animal procedures were carried out in accordance with the NIH guidelines for the Care and Use of Laboratory Animals and approved by the Animal Welfare Committee of the University of Texas Health Science Center at Houston. TRPC1 KO (Trpc1 ${ }^{-/-}$) and quadruple TRPC1, C4, C5, C6 KO (QuadKO) mice (129/SvEv and C57BL/6J mixed background) were created and maintained as described (Dietrich et al., 2007; Formoso et al., 2020); TRPC4 KO (Trpc4 ${ }^{-/}$) in C57BL/6 background were generated and maintained as previously described (Freichel et al., 2001).

\section{Mouse Ischemic Models}

Focal ischemia (intraluminal suture) model of MCAO was carried out for $40 \mathrm{~min}$ followed by reperfusion as previously described (Sun et al., 2019). Animals were male QuadKO mice (8-9 weeks, $\sim 25 \mathrm{~g}$ ) and age-matched wild type controls (C57BL/6J). In the MCA $\backslash$ CCAO model, unilateral occlusion of the left middle cerebral artery (MCA) and the left common carotid artery (CCA) was made as previously described (Aronowski et al., 1994; Zhao et al., 2015) using male wild type C57BL/6J and TRPC4 KO mice (8 weeks old). The occlusion times were 30,90 , and $120 \mathrm{~min}$ followed by reperfusion. With this method, the infarction is limited to the cortical tissue.

\section{Oxygen and Glucose Deprivation (OGD) Models}

Primary cultures of cortical neurons were established using postnatal day 0 mouse pups $(\mathrm{M} / \mathrm{F})$ according to the description (Facci and Skaper, 2012). Cortical tissues from wild type (C57BL/6J), TRPC1 KO, TRPC4 KO, and QuadKO pups were triturated in a papain dissociation solution (Worthington) supplemented with DNase (200 units/ml) and incubated for $1 \mathrm{~h}$ in $37^{\circ} \mathrm{C} \mathrm{CO} 2$ incubator. After stopping the reaction by adding ovomucoid (10 mg/ml), DNase (200 units/ml), and $10 \%$ fetal bovine serum in Earle's balanced salt solution, cells were plated at $2 \times 10^{5}$ per well in $500 \mu \mathrm{l}$ of neurobasal medium supplemented with B27 (Invitrogen) and Glutamax (invitrogen) on polyD-lysine (Sigma)-coated 12-mm round coverslips in 24-well culture plates. Another $500 \mu \mathrm{l}$ of medium with arabinofuranosyl cytidine (1 $\mu \mathrm{M}$ final) was then added, and $20-30 \%$ of the medium was exchanged every other day until the cells were used for experiments (usually 16-18 days). For OGD, the medium was replaced with the deoxygenated glucose-free bicarbonate solution and the plate transferred to an anaerobic incubator containing $5 \% \quad \mathrm{CO}_{2}$ and $94 \% \mathrm{~N}_{2} \quad\left(\begin{array}{lll}1 \% & \mathrm{O}_{2}\end{array}\right)$ atmosphere for $2 \mathrm{~h}$. After OGD, the cells were rinsed with oxygenated glucose (20 $\mathrm{mM}$ )-containing bicarbonate solution, fed with the original neurobasal medium, and cultured for 0 or $24 \mathrm{~h}$ at $37^{\circ} \mathrm{C}, 5 \% \mathrm{CO}_{2}$ (Ying et al., 1997).

Acute brain slices were prepared from wild type and TRPC4 KO mice (M, P15) as previously described (Tian et al., 2014a). Coronal slices $(350 \mu \mathrm{m})$ were incubated in normal artificial cerebrospinal fluid (aCSF) consisting of (in $\mathrm{mM}$ ): $125 \mathrm{NaCl}, 26$ $\mathrm{NaHCO}_{3}, 1 \mathrm{MgSO}_{4}, 2.5 \mathrm{KCl}, 1.25 \mathrm{NaH}_{2} \mathrm{PO}_{4}, 2 \mathrm{CaCl}_{2}$, and 10 glucose, bubbled with $95 \% \mathrm{O}_{2} / 5 \% \mathrm{CO}_{2}$ at $35^{\circ} \mathrm{C}$ for at least $90 \mathrm{~min}$ before experiments. To induce OGD, slices were transferred to $15 \mathrm{ml}$ conical tubes containing aCSF without glucose, which were bubbled with $\mathrm{N}_{2} / \mathrm{CO}_{2}$ at $35^{\circ} \mathrm{C}$ for $30 \mathrm{~min}$. After the OGD treatment, the slices were returned to the glucose containing aCSF bubbled with $95 \% \mathrm{O}_{2} / 5 \% \mathrm{CO}_{2}$ at $35^{\circ} \mathrm{C}$ for $3 \mathrm{~h}$.

\section{DATA AVAILABILITY STATEMENT}

The original contributions generated for this study are included in the article/supplementary materials, further inquiries can be directed to the corresponding author.

\section{ETHICS STATEMENT}

The animal study was reviewed and approved by Animal Welfare Committee of University of Texas Health Science Center at Houston. 


\section{AUTHOR CONTRIBUTIONS}

JJ prepared illustrations and wrote the manuscript. MZ wrote the manuscript. All authors proofread and approved the manuscript.

\section{FUNDING}

This research in the authors' lab was supported by NIH grants R01 NS092377 and R01 NS102452 (to MZ), the intramural Research Program of the NIH (Project Z01-101684 to LB), the American Heart Association Southwest Affiliate grant 15POST22630008 (to JJ), the

\section{REFERENCES}

Akbulut, Y., Gaunt, H. J., Muraki, K., Ludlow, M. J., Amer, M. S., Bruns, A., et al. (2015). (-)-Englerin A is a potent and selective activator of TRPC4 and TRPC5 calcium channels. Angew. Chem. Int. Ed. Engl. 54, 3787-3791. doi: 10.1002/anie.201411511

Alkayed, N. J., Harukuni, I., Kimes, A. S., London, E. D., Traystman, R. J., and Hurn, P. D. (1998). Gender-linked brain injury in experimental stroke. Stroke 29, 159-165. doi: 10.1161/01.str.29.1.159

Amaral, M. D., and Pozzo-Miller, L. (2007). TRPC3 channels are necessary for brain-derived neurotrophic factor to activate a nonselective cationic current and to induce dendritic spine formation. J. Neurosci. 27, 5179-5189. doi: 10. 1523/JNEUROSCI.5499-06.2007

Aronowski, J., Ostrow, P., Samways, E., Strong, R., Zivin, J. A., and Grotta, J. C. (1994). Graded bioassay for demonstration of brain rescue from experimental acute ischemia in rats. Stroke 25, 2235-2240. doi: 10.1161/01.str.25.11.2235

Belkacemi, T., Niermann, A., Hofmann, L., Wissenbach, U., Birnbaumer, L., Leidinger, P., et al. (2017). TRPC1- and TRPC3-dependent $\mathrm{Ca}(2+)$ signaling in mouse cortical astrocytes affects injury-evoked astrogliosis in vivo. Glia 65, 1535-1549. doi: 10.1002/glia.23180

Berridge, M. J. (2009). Inositol trisphosphate and calcium signalling mechanisms. Biochim. Biophys. Acta 1793, 933-940. doi: 10.1016/j.bbamcr.2008.10.005

Bocksch, W., Pomar, F., Dziarmaga, M., Tresukosol, D., Ismail, O., Janek, B., et al. (2010). Clinical safety and efficacy of a novel thin-strut cobalt-chromium coronary stent system: results of the real world coroflex blue registry. Catheter. Cardiovasc. Interv 75, 78-85. doi: 10.1002/ccd.22208

Bonde, C., Noraberg, J., Noer, H., and Zimmer, J. (2005). Ionotropic glutamate receptors and glutamate transporters are involved in necrotic neuronal cell death induced by oxygen-glucose deprivation of hippocampal slice cultures. Neuroscience 136, 779-794. doi: 10.1016/j.neuroscience.2005.07.020

Braeuninger, S., and Kleinschnitz, C. (2009). Rodent models of focal cerebral ischemia: procedural pitfalls and translational problems. Exp. Transl. Stroke Med. 1:8. doi: 10.1186/2040-7378-1-8

Brisson, C. D., and Andrew, R. D. (2012). A neuronal population in hypothalamus that dramatically resists acute ischemic injury compared to neocortex. J. Neurophysiol. 108, 419-430. doi: 10.1152/jn.00090.2012

Broker-Lai, J., Kollewe, A., Schindeldecker, B., Pohle, J., Nguyen Chi, V., Mathar, I., et al. (2017). Heteromeric channels formed by TRPC1, TRPC4 and TRPC5 define hippocampal synaptic transmission and working memory. EMBO J. 36, 2770-2789. doi: 10.15252/embj.201696369

Brust, J. C. M. (2013). Principles of Neural Science, 5th Edn. New York: McGrawHill, 1550-1554.

Carson, C., Raman, P., Tullai, J., Xu, L., Henault, M., Thomas, E., et al. (2015). Englerin a agonizes the TRPC4/C5 cation channels to inhibit tumor cell line proliferation. PLoS One 10:e0127498. doi: 10.1371/journal.pone.0127498

Cederholm, J. M. E., Kim, Y., von Jonquieres, G., and Housley, G. D. (2019). Human brain region-specific alternative splicing of TRPC3, the type 3 canonical transient receptor potential non-selective cation channel. Cerebellum 18, 536543. doi: 10.1007/s12311-019-01026-4

Chen, J., Li, Z., Hatcher, J. T., Chen, Q. H., Chen, L., Wurster, R. D., et al. (2017). Deletion of TRPC6 attenuates NMDA receptor-mediated $\mathrm{Ca}(2+)$ entry and
DZHK (German Centre for Cardiovascular Research), the BMBF (German Ministry of Education and Research), the Deutsche Forschungsgemeinschaft (DFG, German Research Foundation): Project-ID 239283807 - TRR 152 and DFG FOR 2289 (FR1638/3-1 and FR1638/3-2 to MF).

\section{ACKNOWLEDGMENTS}

We thank Prof. Veit Flockerzi (Saarland University, Germany) for the TRPC4 knockout mice.

$\mathrm{Ca}(2+)$-induced neurotoxicity following cerebral ischemia and oxygen-glucose deprivation. Front. Neurosci. 11:138. doi: 10.3389/fnins.2017.00138

Chen, J. M., Li, Q. W., Liu, J. S., Jiang, G. X., Liu, J. R., Chen, S. D., et al. (2019). TRPC6 mRNA levels in peripheral leucocytes of patients with Alzheimer's disease and mild cognitive impairment: a case-control study. Prog. Neuropsychopharmacol. Biol. Psychiatry 92, 279-284. doi: 10.1016/j.pnpbp. 2019.01.009

Chen, M., Liu, J., Lu, Y., Duan, C., Lu, L., Gao, G., et al. (2017). Age-dependent alpha-synuclein accumulation is correlated with elevation of mitochondrial TRPC3 in the brains of monkeys and mice. J. Neural Transm. 124, 441-453. doi: 10.1007/s00702-016-1654-y

Chen, X., Lu, M., He, X., Ma, L., Birnbaumer, L., and Liao, Y. (2017). TRPC3/6/7 knockdown protects the brain from cerebral ischemia injury via astrocyte apoptosis inhibition and effects on NF-small ka, CyrillicB translocation. Mol. Neurobiol. 54, 7555-7566. doi: 10.1007/s12035-016-0227-2

Chernyuk, D., Zernov, N., Kabirova, M., Bezprozvanny, I., and Popugaeva, E. (2019). Antagonist of neuronal store-operated calcium entry exerts beneficial effects in neurons expressing PSEN1DeltaE9 mutant linked to familial Alzheimer disease. Neuroscience 410, 118-127. doi: 10.1016/j.neuroscience. 2019.04.043

Clapham, D. E. (2003). TRP channels as cellular sensors. Nature 426, 517-524. doi: 10.1038/nature02196

Dietrich, A., Kalwa, H., Storch, U., Mederos y Schnitzler, M., Salanova, B. Pinkenburg, O., et al. (2007). Pressure-induced and store-operated cation influx in vascular smooth muscle cells is independent of TRPC1. Pflugers Arch. 455, 465-477. doi: 10.1007/s00424-007-0314-3

Doyle, K. P., Simon, R. P., and Stenzel-Poore, M. P. (2008). Mechanisms of ischemic brain damage. Neuropharmacology 55, 310-318. doi: 10.1016/j. neuropharm.2008.01.005

Du, W., Huang, J., Yao, H., Zhou, K., Duan, B., and Wang, Y. (2010). Inhibition of TRPC6 degradation suppresses ischemic brain damage in rats. J. Clin. Invest. 120, 3480-3492. doi: 10.1172/JCI43165

Durukan, A., and Tatlisumak, T. (2007). Acute ischemic stroke: overview of major experimental rodent models, pathophysiology, and therapy of focal cerebral ischemia. Pharmacol. Biochem. Behav. 87, 179-197. doi: 10.1016/j.pbb.2007. 04.015

El-Hassar, L., Hagenston, A. M., D’Angelo, L. B., and Yeckel, M. F. (2011). Metabotropic glutamate receptors regulate hippocampal CA1 pyramidal neuron excitability via $\mathrm{Ca}(2)(+)$ wave-dependent activation of SK and TRPC channels. J. Physiol. 589(Pt 13), 3211-3229. doi: 10.1113/jphysiol.2011.209783

Elzamzamy, O. M., Penner, R., and Hazlehurst, L. A. (2020). The role of TRPC1 in modulating cancer progression. Cells 9:388. doi: 10.3390/cells 9020388

Facci, L., and Skaper, S. D. (2012). Culture of rodent cortical and hippocampal neurons. Methods Mol. Biol. 846, 49-56. doi: 10.1007/978-1-61779-536-7_5

Feng, S., Li, H., Tai, Y., Huang, J., Su, Y., Abramowitz, J., et al. (2013). Canonical transient receptor potential 3 channels regulate mitochondrial calcium uptake. Proc. Natl. Acad. Sci. U.S.A. 110, 11011-11016. doi: 10.1073/pnas.13095 31110

Formoso, K., Susperreguy, S., Freichel, M., and Birnbaumer, L. (2020). RNA-seq analysis reveals TRPC genes to impact an unexpected number of metabolic and regulatory pathways. Sci. Rep. 10:7227. doi: 10.1038/s41598-020-61177-x 
Fowler, M. A., Sidiropoulou, K., Ozkan, E. D., Phillips, C. W., and Cooper, D. C. (2007). Corticolimbic expression of TRPC4 and TRPC5 channels in the rodent brain. PLoS One 2:e573. doi: 10.1371/journal.pone.0000573

Freichel, M., Suh, S. H., Pfeifer, A., Schweig, U., Trost, C., Weissgerber, P., et al. (2001). Lack of an endothelial store-operated Ca2+ current impairs agonistdependent vasorelaxation in TRP4-/- mice. Nat. Cell Biol. 3, 121-127. doi: $10.1038 / 35055019$

Gao, Y., Yao, T., Deng, Z., Sohn, J. W., Sun, J., Huang, Y., et al. (2017). TrpC5 mediates acute leptin and serotonin effects via pomc neurons. Cell. Rep. 18, 583-592. doi: 10.1016/j.celrep.2016.12.072

Gao, Y. Q., Gao, H., Zhou, Z. Y., Lu, S. D., and Sun, F. Y. (2004). [Expression of transient receptor potential channel 4 in striatum and hippocampus of rats is increased after focal cerebral ischemia]. Sheng Li Xue Bao 56, 153-157.

Gelderblom, M., Weymar, A., Bernreuther, C., Velden, J., Arunachalam, P., Steinbach, K., et al. (2012). Neutralization of the IL-17 axis diminishes neutrophil invasion and protects from ischemic stroke. Blood 120, 3793-3802. doi: 10.1182/blood-2012-02-412726

Gordienko, D. V., and Zholos, A. V. (2004). Regulation of muscarinic cationic current in myocytes from guinea-pig ileum by intracellular $\mathrm{Ca} 2+$ release: a central role of inositol 1,4,5-trisphosphate receptors. Cell Calcium 36, 367-386. doi: 10.1016/j.ceca.2004.02.021

Grant, C. V., Carver, C. M., Hastings, S. D., Ramachandran, K., Muniswamy, M., Risinger, A. L., et al. (2019). Triple-negative breast cancer cell line sensitivity to englerin A identifies a new, targetable subtype. Breast Cancer Res. Treat. 177, 345-355. doi: 10.1007/s10549-019-05324-7

Greka, A., Navarro, B., Oancea, E., Duggan, A., and Clapham, D. E. (2003). TRPC5 is a regulator of hippocampal neurite length and growth cone morphology. Nat. Neurosci. 6, 837-845. doi: 10.1038/nn1092

Guo, C., Ma, Y., Ma, S., Mu, F., Deng, J., Duan, J., et al. (2017). The role of TRPC6 in the neuroprotection of calycosin against cerebral ischemic injury. Sci. Rep. 7:3039. doi: 10.1038/s41598-017-03404-6

Guo, J., Li, J., Xia, L., Wang, Y., Zhu, J., Du, J., et al. (2020). Transient receptor potential canonical 5-scramblase signaling complex mediates neuronal phosphatidylserine externalization and apoptosis. Cells 9:547. doi: 10.3390/ cells 9030547

Hartmann, J., Dragicevic, E., Adelsberger, H., Henning, H. A., Sumser, M., Abramowitz, J., et al. (2008). TRPC3 channels are required for synaptic transmission and motor coordination. Neuron 59, 392-398. doi: 10.1016/j. neuron.2008.06.009

Hille, B., Dickson, E. J., Kruse, M., Vivas, O., and Suh, B. C. (2015). Phosphoinositides regulate ion channels. Biochim. Biophys. Acta 1851, 844-856. doi: 10.1016/j.bbalip.2014.09.010

Hilton, G. D., Nunez, J. L., Bambrick, L., Thompson, S. M., and McCarthy, M. M. (2006). Glutamate-mediated excitotoxicity in neonatal hippocampal neurons is mediated by mGluR-induced release of $\mathrm{Ca}++$ from intracellular stores and is prevented by estradiol. Eur. J. Neurosci. 24, 3008-3016. doi: 10.1111/j.14609568.2006.05189. $\mathrm{x}$

Hong, C., Choi, S. H., Kwak, M., Jeong, B., Ko, J., Park, H. J., et al. (2020). TRPC5 channel instability induced by depalmitoylation protects striatal neurons against oxidative stress in Huntington's disease. Biochim. Biophys. Acta Mol. Cell Res. 1867:118620. doi: 10.1016/j.bbamcr.2019.118620

Hong, C., Seo, H., Kwak, M., Jeon, J., Jang, J., Jeong, E. M., et al. (2015). Increased TRPC5 glutathionylation contributes to striatal neuron loss in Huntington's disease. Brain 138(Pt 10), 3030-3047. doi: 10.1093/brain/awv188

Huang, J., Liu, C. H., Hughes, S. A., Postma, M., Schwiening, C. J., and Hardie, R. C. (2010). Activation of TRP channels by protons and phosphoinositide depletion in Drosophila photoreceptors. Curr. Biol. 20, 189-197. doi: 10.1016/j.cub.2009. 12.019

Ishii, M., Iizuka, R., Kiuchi, Y., Mori, Y., and Shimizu, S. (2011). Neuroprotection by lomerizine, a prophylactic drug for migraine, against hydrogen peroxideinduced hippocampal neurotoxicity. Mol. Cell. Biochem. 358, 1-11. doi: 10. 1007/s11010-011-0913-3

Jeon, J., Tian, J. B., and Zhu, M. X. (2020). TRPC4 as a coincident detector of Gi/o and $\mathrm{Gq} / 11$ signaling: mechanisms and pathophysiological implications. Curr. Opin. Physiol. 17, 34-41. doi: 10.1016/j.cophys.2020.06.008

Jeon, J. P., Roh, S. E., Wie, J., Kim, J., Kim, H., Lee, K. P., et al. (2013). Activation of TRPC4beta by Galphai subunit increases $\mathrm{Ca} 2+$ selectivity and controls neurite morphogenesis in cultured hippocampal neuron. Cell Calcium 54, 307-319. doi: 10.1016/j.ceca.2013.07.006

Kim, D. S., Ryu, H. J., Kim, J. E., and Kang, T. C. (2013). The reverse roles of transient receptor potential canonical channel-3 and -6 in neuronal death following pilocarpine-induced status epilepticus. Cell. Mol. Neurobiol. 33, 99109. doi: 10.1007/s10571-012-9875-6

Kim, J. E., Park, H., Choi, S. H., Kong, M. J., and Kang, T. C. (2019). TRPC6-Mediated ERK1/2 activation increases dentate granule cell resistance to status epilepticus via regulating lon protease- 1 expression and mitochondrial dynamics. Cells 8:1376. doi: 10.3390/cells8111376

Kim, S. J., Kim, Y. S., Yuan, J. P., Petralia, R. S., Worley, P. F., and Linden, D. J. (2003). Activation of the TRPC1 cation channel by metabotropic glutamate receptor mGluR1. Nature 426, 285-291. doi: 10.1038/nature02162

Kim, Y. J., and Kang, T. C. (2015). The role of TRPC6 in seizure susceptibility and seizure-related neuronal damage in the rat dentate gyrus. Neuroscience 307 , 215-230. doi: 10.1016/j.neuroscience.2015.08.054

Ko, A. R., and Kang, T. C. (2017). TRPC6-mediated ERK1/2 phosphorylation prevents dentate granule cell degeneration via inhibiting mitochondrial elongation. Neuropharmacology 121, 120-129. doi: 10.1016/j.neuropharm.2017. 05.004

Kondratskyi, A., Kondratska, K., Skryma, R., and Prevarskaya, N. (2015). Ion channels in the regulation of apoptosis. Biochim. Biophys. Acta 1848(10 Pt B), 2532-2546. doi: 10.1016/j.bbamem.2014.10.030

Lankiewicz, S., Marc Luetjens, C., Truc Bui, N., Krohn, A. J., Poppe, M., Cole, G. M., et al. (2000). Activation of calpain I converts excitotoxic neuron death into a caspase-independent cell death. J. Biol. Chem. 275, 17064-17071. doi: $10.1074 /$ jbc. 275.22 .17064

Lessard, C. B., Lussier, M. P., Cayouette, S., Bourque, G., and Boulay, G. (2005). The overexpression of presenilin2 and Alzheimer's-disease-linked presenilin2 variants influences TRPC6-enhanced Ca2+ entry into HEK293 cells. Cell. Signal. 17, 437-445. doi: 10.1016/j.cellsig.2004.09.005

Leuner, K., Kazanski, V., Müller, M., Essin, K., Henke, B., Gollasch, M., et al. (2007). Hyperforin-a key constituent of St. John's wort specifically activates TRPC6 channels. FASEB J. 21, 4101-4111. doi: 10.1096/fj.07-8110com

Li, H., Huang, J., Du, W., Jia, C., Yao, H., and Wang, Y. (2012). TRPC6 inhibited NMDA receptor activities and protected neurons from ischemic excitotoxicity. J. Neurochem. 123, 1010-1018. doi: 10.1111/jnc. 12045

Li, J., Siegel, M., Yuan, M., Zeng, Z., Finnucan, L., Persky, R., et al. (2011). Estrogen enhances neurogenesis and behavioral recovery after stroke. J. Cereb. Blood Flow Metab. 31, 413-425. doi: 10.1038/jcbfm.2010.181

Li, M., Liu, E., Zhou, Q., Li, S., Wang, X., Liu, Y., et al. (2018). TRPC1 null exacerbates memory deficit and apoptosis induced by Amyloid-beta. J. Alzheimers. Dis. 63, 761-772. doi: 10.3233/JAD-180077

Li, Y., Calfa, G., Inoue, T., Amaral, M. D., and Pozzo-Miller, L. (2010). Activitydependent release of endogenous BDNF from mossy fibers evokes a TRPC3 current and Ca2+elevations in CA3 pyramidal neurons. J. Neurophysiol. 103, 2846-2856. doi: 10.1152/jn.01140.2009

Liman, E. R., Corey, D. P., and Dulac, C. (1999). TRP2: a candidate transduction channel for mammalian pheromone sensory signaling. Proc. Natl. Acad. Sci. U.S.A. 96, 5791-5796. doi: 10.1073/pnas.96.10.5791

Lin, Y., Chen, F., Zhang, J., Wang, T., Wei, X., Wu, J., et al. (2013a). Neuroprotective effect of resveratrol on ischemia/reperfusion injury in rats through TRPC6/CREB pathways. J. Mol. Neurosci. 50, 504-513. doi: 10.1007/ s12031-013-9977-8

Lin, Y., Zhang, J. C., Fu, J., Chen, F., Wang, J., Wu, Z. L., et al. (2013b). Hyperforin attenuates brain damage induced by transient middle cerebral artery occlusion (MCAO) in rats via inhibition of TRPC6 channels degradation. J. Cereb. Blood Flow Metab. 33, 253-262. doi: 10.1038/jcbfm.2012.164

Lipton, P. (1999). Ischemic cell death in brain neurons. Physiol. Rev. 79, 1431-1568. doi: 10.1152/physrev.1999.79.4.1431

Lo, E. H., Dalkara, T., and Moskowitz, M. A. (2003). Mechanisms, challenges and opportunities in stroke. Nat. Rev. Neurosci. 4, 399-415. doi: 10.1038/nrn1106

Logothetis, D. E., Mahajan, R., Adney, S. K., Ha, J., Kawano, T., Meng, X. Y., et al. (2015). Unifying mechanism of controlling Kir3 channel activity by G proteins and phosphoinositides. Int. Rev. Neurobiol. 123, 1-26. doi: 10.1016/bs.irn.2015. 05.013

Lu, R., Wang, J., Tao, R., Wang, J., Zhu, T., Guo, W., et al. (2018). Reduced TRPC6 mRNA levels in the blood cells of patients with Alzheimer's disease and 
mild cognitive impairment. Mol. Psychiatry 23, 767-776. doi: 10.1038/mp.20 17.136

Ludlow, M. J., Gaunt, H. J., Rubaiy, H. N., Musialowski, K. E., Blythe, N. M., Vasudev, N. S., et al. (2017). (-)-Englerin A-evoked cytotoxicity is mediated by $\mathrm{Na}+$ influx and counteracted by $\mathrm{Na}+\mathrm{K}+-\mathrm{ATPase}$. J. Biol. Chem. 292, 723-731. doi: 10.1074/jbc.M116.755678

Maher, P., van Leyen, K., Dey, P. N., Honrath, B., Dolga, A., and Methner, A. (2018). The role of $\mathrm{Ca}(2+)$ in cell death caused by oxidative glutamate toxicity and ferroptosis. Cell Calcium 70, 47-55. doi: 10.1016/j.ceca.2017.05.007

Miller, M., Shi, J., Zhu, Y., Kustov, M., Tian, J. B., Stevens, A., et al. (2011). Identification of ML204, a novel potent antagonist that selectively modulates native TRPC4/C5 ion channels. J. Biol. Chem. 286, 33436-33446. doi: 10.1074/ jbc.M111.274167

Montell, C., Birnbaumer, L., Flockerzi, V., Bindels, R. J., Bruford, E. A., Caterina, M. J., et al. (2002). A unified nomenclature for the superfamily of TRP cation channels. Mol. Cell. 9, 229-231. doi: 10.1016/s1097-2765(02)00448-3

Munakata, M., Shirakawa, H., Nagayasu, K., Miyanohara, J., Miyake, T., Nakagawa, T., et al. (2013). Transient receptor potential canonical 3 inhibitor Pyr3 improves outcomes and attenuates astrogliosis after intracerebral hemorrhage in mice. Stroke 44, 1981-1987. doi: 10.1161/STROKEAHA.113.679332

Munsch, T., Freichel, M., Flockerzi, V., and Pape, H. C. (2003). Contribution of transient receptor potential channels to the control of GABA release from dendrites. Proc. Natl. Acad. Sci. U.S.A. 100, 16065-16070. doi: 10.1073/pnas. 2535311100

Myeong, J., Ko, J., Kwak, M., Kim, J., Woo, J., Ha, K., et al. (2018). Dual action of the Galphaq-PLCbeta-PI(4,5)P2 pathway on TRPC1/4 and TRPC1/5 heterotetramers. Sci. Rep. 8:12117. doi: 10.1038/s41598-018-30625-0

Nair, S., Hagberg, H., Krishnamurthy, R., Thornton, C., and Mallard, C. (2013). Death associated protein kinases: molecular structure and brain injury. Int. J. Mol. Sci. 14, 13858-13872. doi: 10.3390/ijms140713858

Ogawa, N., Kurokawa, T., and Mori, Y. (2016). Sensing of redox status by TRP channels. Cell Calcium 60, 115-122. doi: 10.1016/j.ceca.2016.02.009

Okada, T., Inoue, R., Yamazaki, K., Maeda, A., Kurosaki, T., Yamakuni, T., et al. (1999). Molecular and functional characterization of a novel mouse transient receptor potential protein homologue TRP7. $\mathrm{Ca}(2+)$-permeable cation channel that is constitutively activated and enhanced by stimulation of $\mathrm{G}$ proteincoupled receptor. J. Biol. Chem. 274, 27359-27370. doi: 10.1074/jbc.274.39. 27359

Otsuguro, K., Tang, J., Tang, Y., Xiao, R., Freichel, M., Tsvilovskyy, V., et al. (2008). Isoform-specific inhibition of TRPC4 channel by phosphatidylinositol 4,5-bisphosphate. J. Biol. Chem. 283, 10026-10036. doi: 10.1074/jbc.M7073 06200

Park, M. K., Choi, B. Y., Kho, A. R., Lee, S. H., Hong, D. K., Jeong, J. H., et al. (2020). Effects of transient receptor potential cation 5 (TRPC5) inhibitor, NU6027, on hippocampal neuronal death after traumatic brain injury. Int. J. Mol. Sci. 21:8256. doi: 10.3390/ijms21218256

Park, S. E., Song, J. H., Hong, C., Kim, D. E., Sul, J. W., Kim, T. Y., et al. (2019). Contribution of zinc-dependent delayed calcium influx via TRPC5 in oxidative neuronal death and its prevention by novel TRPC antagonist. Mol. Neurobiol. 56, 2822-2835. doi: 10.1007/s12035-018-1258-1257

Phelan, K. D., Mock, M. M., Kretz, O., Shwe, U. T., Kozhemyakin, M., Greenfield, L. J., et al. (2012). Heteromeric canonical transient receptor potential 1 and 4 channels play a critical role in epileptiform burst firing and seizure-induced neurodegeneration. Mol. Pharmacol. 81, 384-392. doi: 10.1124/mol.111. 075341

Phelan, K. D., Shwe, U. T., Abramowitz, J., Wu, H., Rhee, S. W., Howell, M. D., et al. (2013). Canonical transient receptor channel 5 (TRPC5) and TRPC1/4 contribute to seizure and excitotoxicity by distinct cellular mechanisms. Mol. Pharmacol. 83, 429-438. doi: 10.1124/mol.112.082271

Popugaeva, E., Chernyuk, D., Zhang, H., Postnikova, T. Y., Pats, K., Fedorova, E., et al. (2019). Derivatives of piperazines as potential therapeutic agents for Alzheimer's disease. Mol. Pharmacol. 95, 337-348. doi: 10.1124/mol.118. 114348

Pressler, R. T., and Regehr, W. G. (2013). Metabotropic glutamate receptors drive global persistent inhibition in the visual thalamus. J. Neurosci. 33, 2494-2506. doi: 10.1523/JNEUROSCI.3458-12.2013

Putney, J. W. (2017). Store-operated calcium entry: an historical overview. Adv. Exp. Med. Biol. 981, 205-214. doi: 10.1007/978-3-319-55858-5_9
Qiu, J., Fang, Y., Ronnekleiv, O. K., and Kelly, M. J. (2010). Leptin excites proopiomelanocortin neurons via activation of TRPC channels. J. Neurosci. 30, 1560-1565. doi: 10.1523/JNEUROSCI.4816-09.2010

Rami, A., and Kogel, D. (2008). Apoptosis meets autophagy-like cell death in the ischemic penumbra: two sides of the same coin? Autophagy 4, 422-426. doi: 10.4161/auto.5778

Rathore, S. S., Hinn, A. R., Cooper, L. S., Tyroler, H. A., and Rosamond, W. D. (2002). Characterization of incident stroke signs and symptoms: findings from the atherosclerosis risk in communities study. Stroke 33, 2718-2721. doi: 10. 1161/01.str.0000035286.87503.31

Reiner, A., and Levitz, J. (2018). Glutamatergic signaling in the central nervous system: ionotropic and metabotropic receptors in concert. Neuron 98, 10801098. doi: 10.1016/j.neuron.2018.05.018

Riccio, A., Li, Y., Moon, J., Kim, K. S., Smith, K. S., Rudolph, U., et al. (2009). Essential role for TRPC5 in amygdala function and fear-related behavior. Cell 137, 761-772. doi: 10.1016/j.cell.2009.03.039

Riccio, A., Li, Y., Tsvetkov, E., Gapon, S., Yao, G. L., Smith, K. S., et al. (2014). Decreased anxiety-like behavior and Galphaq/11-dependent responses in the amygdala of mice lacking TRPC4 channels. J. Neurosci. 34, 3653-3667. doi: 10.1523/JNEUROSCI.2274-13.2014

Riccio, A., Medhurst, A. D., Mattei, C., Kelsell, R. E., Calver, A. R., Randall, A. D., et al. (2002). mRNA distribution analysis of human TRPC family in CNS and peripheral tissues. Brain Res. Mol. Brain Res. 109, 95-104. doi: 10.1016/s0169$328 \mathrm{x}(02) 00527-2$

Sell, T. S., Belkacemi, T., Flockerzi, V., and Beck, A. (2014). Protonophore properties of hyperforin are essential for its pharmacological activity. Sci. Rep. 4:7500. doi: 10.1038/srep07500

Selvaraj, S., Sun, Y., Watt, J. A., Wang, S., Lei, S., Birnbaumer, L., et al. (2012). Neurotoxin-induced ER stress in mouse dopaminergic neurons involves downregulation of TRPC1 and inhibition of AKT/mTOR signaling. J. Clin. Invest. 122, 1354-1367. doi: 10.1172/JCI61332

Shamloo, M., Soriano, L., Wieloch, T., Nikolich, K., Urfer, R., and Oksenberg, D. (2005). Death-associated protein kinase is activated by dephosphorylation in response to cerebral ischemia. J. Biol. Chem. 280, 42290-42299. doi: 10.1074/ jbc.M505804200

Shen, N., Wang, L., Wu, Y., Liu, Y., Pei, H., and Xiang, H. (2020). Adeno-associated virus packaged TRPC5 gene therapy alleviated spinal cord ischemic reperfusion injury in rats. Neuroreport 31, 29-36. doi: 10.1097/WNR.00000000000 01359

Shirakawa, H., Sakimoto, S., Nakao, K., Sugishita, A., Konno, M., Iida, S., et al. (2010). Transient receptor potential canonical 3 (TRPC3) mediates thrombininduced astrocyte activation and upregulates its own expression in cortical astrocytes. J. Neurosci. 30, 13116-13129. doi: 10.1523/JNEUROSCI.1890-10. 2010

Simpkins, K. L., Guttmann, R. P., Dong, Y., Chen, Z., Sokol, S., Neumar, R. W., et al. (2003). Selective activation induced cleavage of the NR2B subunit by calpain. J. Neurosci. 23, 11322-11331.

Sohn, J. W., Xu, Y., Jones, J. E., Wickman, K., Williams, K. W., and Elmquist, J. K. (2011). Serotonin 2C receptor activates a distinct population of arcuate pro-opiomelanocortin neurons via TRPC channels. Neuron 71, 488-497. doi: 10.1016/j.neuron.2011.06.012

Storch, U., Forst, A. L., Pardatscher, F., Erdogmus, S., Philipp, M., Gregoritza, M., et al. (2017). Dynamic NHERF interaction with TRPC4/5 proteins is required for channel gating by diacylglycerol. Proc. Natl. Acad. Sci. U.S.A. 114, E37-E46. doi: 10.1073/pnas.1612263114

Storch, U., Forst, A. L., Philipp, M., Gudermann, T., and Mederos y Schnitzler, M. (2012). Transient receptor potential channel 1 (TRPC1) reduces calcium permeability in heteromeric channel complexes. J. Biol. Chem. 287, 3530-3540. doi: 10.1074/jbc.M111.283218

Strubing, C., Krapivinsky, G., Krapivinsky, L., and Clapham, D. E. (2001). TRPC1 and TRPC5 form a novel cation channel in mammalian brain. Neuron 29, 645-655. doi: 10.1016/s0896-6273(01)00240-9

Sukumaran, P., Sun, Y., Antonson, N., and Singh, B. B. (2018). Dopaminergic neurotoxins induce cell death by attenuating NF-kappaB-mediated regulation of TRPC1 expression and autophagy. FASEB J. 32, 1640-1652. doi: 10.1096/fj. 201700662RR

Sun, P., Bu, F., Min, J. W., Munshi, Y., Howe, M. D., Liu, L., et al. (2019). Inhibition of calcium/calmodulin-dependent protein kinase kinase (CaMKK) exacerbates 
impairment of endothelial cell and blood-brain barrier after stroke. Eur. J. Neurosci. 49, 27-39. doi: 10.1111/ejn.14223

Sun, Y., Sukumaran, P., and Singh, B. B. (2020). Sigmal receptor inhibits TRPC1mediated $\mathrm{Ca}(2+)$ entry that promotes dopaminergic cell death. Cell Mol. Neurobiol. [Epub ahead of print]. doi: 10.1007/s10571-020-00892-5

Sun, Y., Zhang, H., Selvaraj, S., Sukumaran, P., Lei, S., Birnbaumer, L., et al. (2017). Inhibition of L-Type $\mathrm{Ca}(2+)$ Channels by TRPC1-STIM1 Complex Is Essential for the Protection of Dopaminergic Neurons. J. Neurosci. 37, 3364-3377. doi: 10.1523/JNEUROSCI.3010-16.2017

Swanson, C. J., Bures, M., Johnson, M. P., Linden, A. M., Monn, J. A., and Schoepp, D. D. (2005). Metabotropic glutamate receptors as novel targets for anxiety and stress disorders. Nat. Rev. Drug Discov. 4, 131-144. doi: 10.1038/nrd 1630

Tabarean, I. V. (2012). Persistent histamine excitation of glutamatergic preoptic neurons. PLoS One 7:e47700. doi: 10.1371/journal.pone.0047700

Tai, C., Hines, D. J., Choi, H. B., and MacVicar, B. A. (2011). Plasma membrane insertion of TRPC5 channels contributes to the cholinergic plateau potential in hippocampal CA1 pyramidal neurons. Hippocampus 21, 958-967. doi: 10.1002/ hipo. 20807

Tanaka, E., Yamamoto, S., Inokuchi, H., Isagai, T., and Higashi, H. (1999). Membrane dysfunction induced by in vitro ischemia in rat hippocampal CA1 pyramidal neurons. J. Neurophysiol. 81, 1872-1880. doi: 10.1152/jn.1999.81.4. 1872

Tanaka, E., Yamamoto, S., Kudo, Y., Mihara, S., and Higashi, H. (1997). Mechanisms underlying the rapid depolarization produced by deprivation of oxygen and glucose in rat hippocampal CA1 neurons in vitro. J. Neurophysiol. 78, 891-902. doi: 10.1152/jn.1997.78.2.891

Tao, R., Lu, R., Wang, J., Zeng, S., Zhang, T., Guo, W., et al. (2020). Probing the therapeutic potential of TRPC6 for Alzheimer's disease in live neurons from patient-specific iPSCs. J. Mol. Cell. Biol. [Epub ahead of print]. doi: 10.1093/ jmcb/mjaa027

Tasca, C. I., Dal-Cim, T., and Cimarosti, H. (2015). In vitro oxygen-glucose deprivation to study ischemic cell death. Methods Mol. Biol. 1254, 197-210. doi: 10.1007/978-1-4939-2152-2_15

Tavafoghi, M., Brodusch, N., Gauvin, R., and Cerruti, M. (2016). Hydroxyapatite formation on graphene oxide modified with amino acids: arginine versus glutamic acid. J. R. Soc. Interface 13:20150986. doi: 10.1098/rsif.2015. 0986

Taylor, C. P., Weber, M. L., Gaughan, C. L., Lehning, E. J., and LoPachin, R. M. (1999). Oxygen/glucose deprivation in hippocampal slices: altered intraneuronal elemental composition predicts structural and functional damage. J. Neurosci. 19, 619-629.

Thakur, D. P., Tian, J. B., Jeon, J., Xiong, J., Huang, Y., Flockerzi, V., et al. (2016). Critical roles of Gi/o proteins and phospholipase C-deltal in the activation of receptor-operated TRPC4 channels. Proc. Natl. Acad. Sci. U.S.A. 113, 10921097. doi: 10.1073/pnas.1522294113

Thakur, D. P., Wang, Q., Jeon, J., Tian, J. B., and Zhu, M. X. (2020). Intracellular acidification facilitates receptor-operated TRPC4 activation through PLCdeltal in a $\mathrm{Ca}(2+)$-dependent manner. J. Physiol. 598, 2651-2667. doi: 10.1113/ JP279658

Tian, J., Thakur, D. P., Lu, Y., Zhu, Y., Freichel, M., Flockerzi, V., et al. (2014a). Dual depolarization responses generated within the same lateral septal neurons by TRPC4-containing channels. Pflugers. Arch. 466, 1301-1316. doi: 10.1007/ s00424-013-1362-5

Tian, J., Thakur, D. P., and Zhu, M. X. (2014b). TRPC channels. Handb. Ion Chann. 27, 411-426.

Toyoda, H., Kawano, T., Sato, H., and Kato, T. (2020). Cellular mechanisms underlying the rapid depolarization caused by oxygen and glucose deprivation in layer III pyramidal cells of the somatosensory cortex. Neurosci. Res. [Epub ahead of print]. doi: 10.1016/j.neures.2020.03.003

Venkatachalam, K., and Montell, C. (2007). TRP channels. Annu. Rev. Biochem. 76, 387-417. doi: 10.1146/annurev.biochem.75.103004.142819

Virani, S. S., Alonso, A., Benjamin, E. J., Bittencourt, M. S., Callaway, C. W., Carson, A. P., et al. (2020). Heart disease and stroke statistics-2020 update: a report from the american heart association. Circulation 141, e139-e596. doi: 10.1161/CIR.0000000000000757

Wang, H., Cheng, X., Tian, J., Xiao, Y., Tian, T., Xu, F., et al. (2020). TRPC channels: structure, function, regulation and recent advances in small molecular probes. Pharmacol. Ther. 209:107497. doi: 10.1016/j.pharmthera.2020. 107497

Wang, J., Lu, R., Yang, J., Li, H., He, Z., Jing, N., et al. (2015). TRPC6 specifically interacts with APP to inhibit its cleavage by gamma-secretase and reduce Abeta production. Nat. Commun. 6:8876. doi: 10.1038/ncomms9876

Wang, S., Zhang, A. P., Kurada, L., Matsui, T., and Lei, S. (2011). Cholecystokinin facilitates neuronal excitability in the entorhinal cortex via activation of TRPClike channels. J. Neurophysiol. 106, 1515-1524. doi: 10.1152/jn.00025.2011

Wang, Z., Wang, Y., Tian, X., Shen, H., Dou, Y., Li, H., et al. (2016). Transient receptor potential channel $1 / 4$ reduces subarachnoid hemorrhage-induced early brain injury in rats via calcineurin-mediated NMDAR and NFAT dephosphorylation. Sci. Rep. 6:33577. doi: 10.1038/srep33577

Woodruff, T. M., Thundyil, J., Tang, S. C., Sobey, C. G., Taylor, S. M., and Arumugam, T. V. (2011). Pathophysiology, treatment, and animal and cellular models of human ischemic stroke. Mol. Neurodegener. 6:11. doi: 10.1186/17501326-6-11

Wu, J., Ryskamp, D., Birnbaumer, L., and Bezprozvanny, I. (2018). Inhibition of TRPC1-dependent store-operated calcium entry improves synaptic stability and motor performance in a mouse model of Huntington's disease. J. Huntingtons. Dis. 7, 35-50. doi: 10.3233/JHD-170266

Wu, J., Shih, H. P., Vigont, V., Hrdlicka, L., Diggins, L., Singh, C., et al. (2011). Neuronal store-operated calcium entry pathway as a novel therapeutic target for Huntington's disease treatment. Chem. Biol. 18, 777-793. doi: 10.1016/j. chembiol.2011.04.012

Xu, N., Meng, H., Liu, T., Feng, Y., Qi, Y., and Wang, H. (2018). TRPC1 deficiency exacerbates cerebral ischemia/reperfusion-induced neurological injury by potentiating Nox4-derived reactive oxygen species generation. Cell Physiol. Biochem. 51, 1723-1738. doi: 10.1159/000495676

Xu, S. Z., Sukumar, P., Zeng, F., Li, J., Jairaman, A., English, A., et al. (2008). TRPC channel activation by extracellular thioredoxin. Nature 451, 69-72. doi: 10.1038 /nature06414

Yan, H. D., Villalobos, C., and Andrade, R. (2009). TRPC channels mediate a muscarinic receptor-induced afterdepolarization in cerebral cortex. J. Neurosci. 29, 10038-10046. doi: 10.1523/JNEUROSCI.1042-09.2009

Yao, C., Zhang, J., Chen, F., and Lin, Y. (2013). Neuroprotectin D1 attenuates brain damage induced by transient middle cerebral artery occlusion in rats through TRPC6/CREB pathways. Mol. Med. Rep. 8, 543-550. doi: 10.3892/mmr.2013. 1543

Yao, C., Zhang, J., Liu, G., Chen, F., and Lin, Y. (2014). Neuroprotection by (-)-epigallocatechin-3-gallate in a rat model of stroke is mediated through inhibition of endoplasmic reticulum stress. Mol. Med. Rep. 9, 69-76. doi: 10. 3892/mmr.2013.1778

Ying, H. S., Weishaupt, J. H., Grabb, M., Canzoniero, L. M., Sensi, S. L., Sheline, C. T., et al. (1997). Sublethal oxygen-glucose deprivation alters hippocampal neuronal AMPA receptor expression and vulnerability to kainate-induced death. J. Neurosci. 17, 9536-9544.

Yoshida, T., Inoue, R., Morii, T., Takahashi, N., Yamamoto, S., Hara, Y., et al. (2006). Nitric oxide activates TRP channels by cysteine S-nitrosylation. Nat. Chem. Biol. 2, 596-607. doi: 10.1038/nchembio821

Zhang, C., Roepke, T. A., Kelly, M. J., and Ronnekleiv, O. K. (2008). Kisspeptin depolarizes gonadotropin-releasing hormone neurons through activation of TRPC-like cationic channels. J. Neurosci. 28, 4423-4434. doi: 10.1523/ JNEUROSCI.5352-07.2008

Zhang, H., Sun, S., Wu, L., Pchitskaya, E., Zakharova, O., Fon Tacer, K., et al. (2016). Store-operated calcium channel complex in postsynaptic spines: a new therapeutic target for Alzheimer's disease treatment. J. Neurosci. 36, 1183711850. doi: 10.1523/JNEUROSCI.1188-16.2016

Zhang, J., Mao, X., Zhou, T., Cheng, X., and Lin, Y. (2014). IL-17A contributes to brain ischemia reperfusion injury through calpain-TRPC6 pathway in mice. Neuroscience 274, 419-428. doi: 10.1016/j.neuroscience.2014.06.001

Zhang, L., Kolaj, M., and Renaud, L. P. (2015). Intracellular postsynaptic cannabinoid receptors link thyrotropin-releasing hormone receptors to TRPClike channels in thalamic paraventricular nucleus neurons. Neuroscience 311, 81-91. doi: 10.1016/j.neuroscience.2015.10.015

Zhao, X., Wang, H., Sun, G., Zhang, J., Edwards, N. J., and Aronowski, J. (2015). Neuronal interleukin- 4 as a modulator of microglial pathways and ischemic brain damage. J. Neurosci. 35, 11281-11291. doi: 10.1523/JNEUROSCI.168515.2015 
Zheng, F., and Phelan, K. D. (2014). The role of canonical transient receptor potential channels in seizure and excitotoxicity. Cells 3, 288-303. doi: 10.3390/ cells3020288

Zhu, Y., Gao, M., Zhou, T., Xie, M., Mao, A., Feng, L., et al. (2019). The TRPC5 channel regulates angiogenesis and promotes recovery from ischemic injury in mice. J. Biol. Chem. 294, 28-37. doi: 10.1074/jbc.RA118. 005392

Zhu, Y., Lu, Y., Qu, C., Miller, M., Tian, J., Thakur, D. P., et al. (2015). Identification and optimization of 2-aminobenzimidazole derivatives as novel inhibitors of TRPC4 and TRPC5 channels. Br. J. Pharmacol. 172, 3495-3509. doi: 10.1111/ bph. 13140
Conflict of Interest: The authors declare that the research was conducted in the absence of any commercial or financial relationships that could be construed as a potential conflict of interest.

Copyright (C) 2021 Jeon, Bu, Sun, Tian, Ting, Li, Aronowski, Birnbaumer, Freichel and Zhu. This is an open-access article distributed under the terms of the Creative Commons Attribution License (CC BY). The use, distribution or reproduction in other forums is permitted, provided the original author(s) and the copyright owner(s) are credited and that the original publication in this journal is cited, in accordance with accepted academic practice. No use, distribution or reproduction is permitted which does not comply with these terms. 